\begin{abstract}
DONDERO, WILLIAM EDWARD. Morphological and Mechanical Properties of Carbon Nanotube/Polymer Composite via Melt Compounding (Under the direction of Russell E. Gorga)
\end{abstract}

The mechanical properties and morphology of multi-wall carbon nanotube (MWNT)/polypropylene (PP) nanocomposites were studied as a function of nanotube orientation and concentration. Through melt mixing followed by melt drawing, using a twin screw mini-extruder with a specially designed winding apparatus, the dispersion and orientation of multi-wall carbon nanotubes was optimized in polypropylene. Tensile tests showed a $32 \%$ increase in toughness for a $0.25 \mathrm{wt} \%$ MWNT in PP (over pure PP). Moreover, modulus increased by $138 \%$ with 0.25 wt $\%$ MWNTs. Transmission electron microscopy (TEM) and scanning electron microscopy (SEM) all demonstrated qualitative nanotube dispersion and orientation. Wide angle X-ray diffraction was used to study crystal morphology and orientation by calculating the Herman's Orientation Factor for the composites as function of nanotube loading and orientation. The addition of nanotubes to oriented samples causes the crystalline morphology to shift from $\alpha$ and mesophase to only $\alpha$ phase. Furthermore, the addition of nanotubes (without orientation) was found to cause isotropization of the PP crystal and drawing was shown to improve crystal orientation through the orientation factor. In addition, differential scanning caloriometry (DSC) qualitatively revealed little change in overall crystallinity. In conclusion this work has shown that melt mixing coupled with melt drawing has yielded MWNT/PP composites with a 
unique combination of strength and toughness suitable for advanced fiber applications, such as smart fibers and high performance fabrics. 


\title{
MORPHOLOGICAL AND MECHANICAL PROPERTIES OF CARBON NANOTUBE/POLYMER COMPOSITES VIA MELT COMPOUNDING
}

by

\section{WILLIAM E. DONDERO}

A thesis submitted to the Graduate Faculty of

North Carolina State University in partial fulfillment of the requirements for the Degree of Master of Science

TEXTILE ENGINEERING

\author{
Raleigh
}

2005

\section{APPROVED BY}

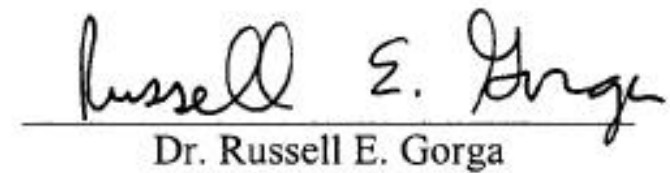

(Chair of Advisory Committee)
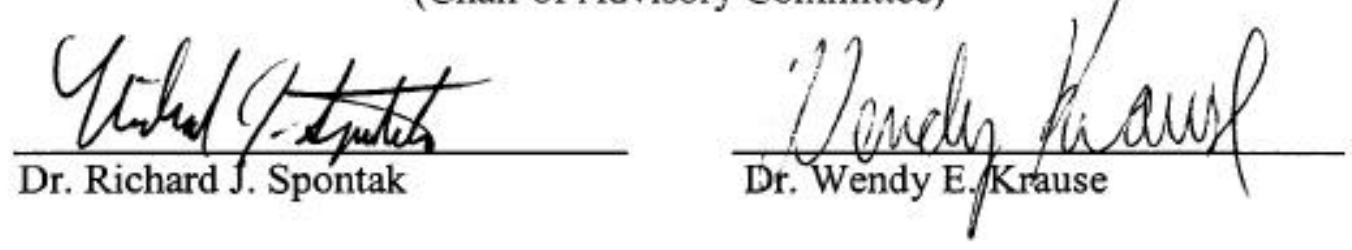


\section{DEDICATION}

This work is dedicated to my family whose encouragement and support made my success possible. 


\section{BIOGRAPHY}

WILLIAM (Billy) E. DONDERO was born in Atlanta, GA on January $25^{\text {th }}, 1980$. In 1998 , he graduated with highest honors from Shiloh High School in Snellville, GA. Billy began his college career at Georgia Institute of Technology in Computer Science. After deciding computer programming was not his ideal career, he transferred to the School of Polymer, Textile, and Fiber Engineering at Georgia Tech and received a Bachelor of Science degree with highest honors in Polymer and Fiber Engineering in 2003. Upon graduating, Billy moved to Raleigh, North Carolina to pursue a Master of Science Degree in Textile Engineering at North Carolina State University in the College of Textiles. 


\section{ACKNOWLEDGEMENTS}

I would like to thank my advisor, Dr. Russell E. Gorga, for his guidance and support. I also thank Dr. Richard J. Spontak and Dr. Wendy E. Krause for being committee members and assistance with my research. Dr. Jon-Paul Maria has provided valuable insight with wide angle X-ray diffraction techniques and analysis. I thank Dr. Sam M. Hudson for supplying polymer and assistance with molecular weight determination. Dr. Behnam Pourdeyhimi and his NCRC lab managers provided extrusion and testing equipment. Birgit Andersen assisted with polymer characterization techniques. I thank Jesse Wood, Isaac Tripp, and Peter Lam for their help and support.

Thanks to my parents, Bill and Patty Dondero, for their love and support. Thanks to my loving wife, Jennifer, for all her love and support. 


\section{TABLE OF CONTENTS}

List of Tables vii

List of Figures viii

List of Figures viii

1. Introduction

\section{1}

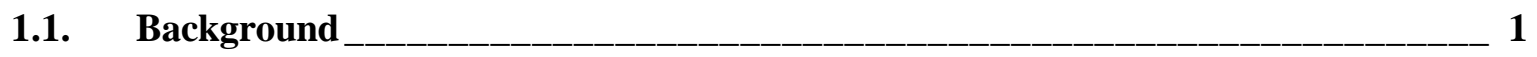

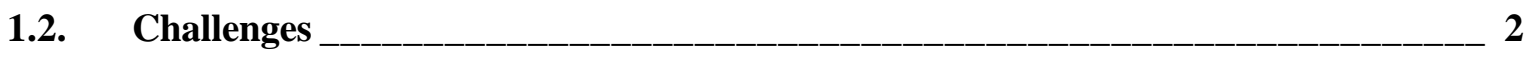

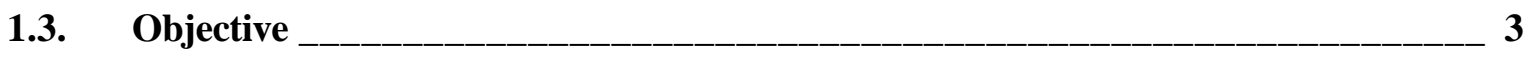

2. Literature Review___ 4

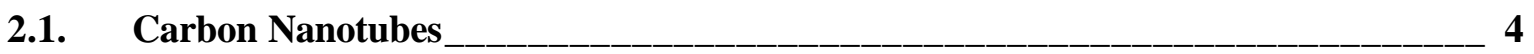

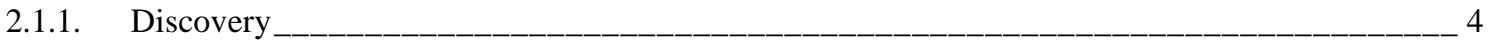

2.1.2. Production Methods

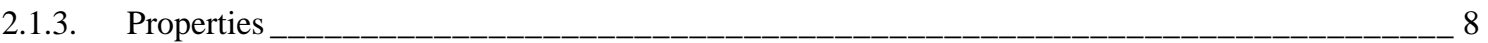

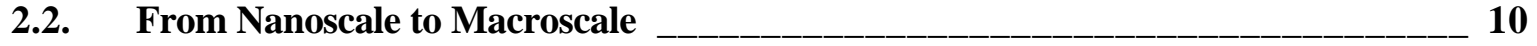

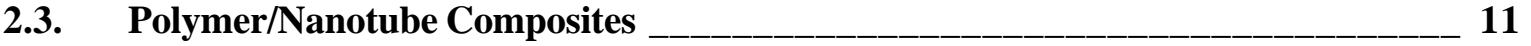

2.3.1. Filler Dispersion and Orientation

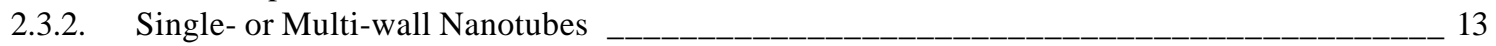

2.3.3. Matrix Material

2.3.4. Polypropylene/Nanotube Composites

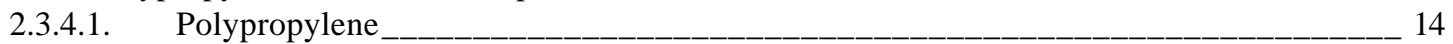

2.3.4.2. Crystallization

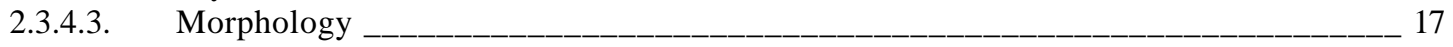

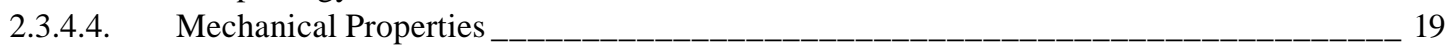

2.4. Conclusion____-__-_-__-_-_-_-_-_-_-_-_-_-_-_-_-_-_-_-_-_-_- 21

3. Experimental __ 23

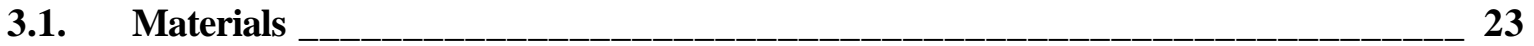

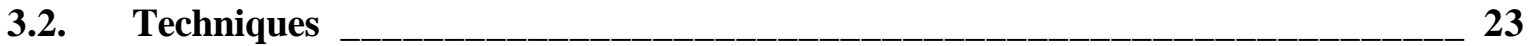

3.2.1. Composite Preparation _-_-_-_-_-_ 23

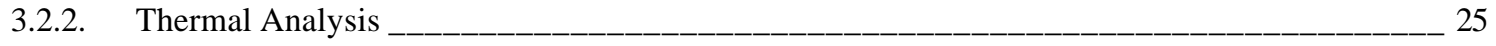

3.2.2.1. Thermal Gravimetric Analysis

3.2.2.2. Differential Scanning Calorimetry

3.2.3. Mechanical Properties _-_-_ 26

3.2.3.1. Tensile 26

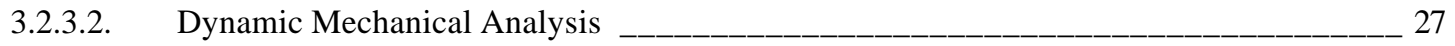

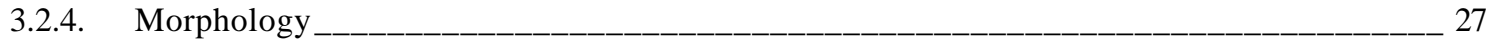

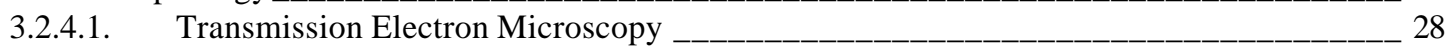

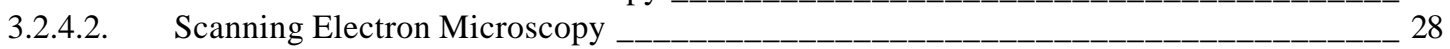

3.2.4.3. Wide Angle X-ray Diffraction

4. Results and Discussion __ 30

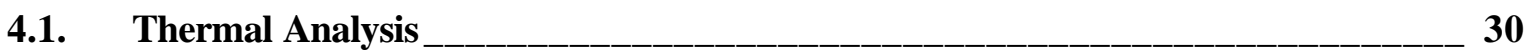

4.1.1. Thermal Gravimetric Analysis _-_-_-_-_-_-_-_-_-_-_-_ 30

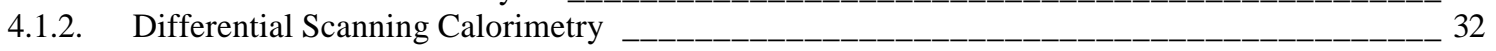




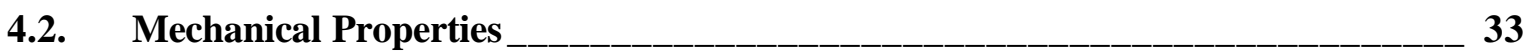

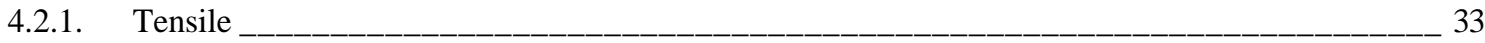

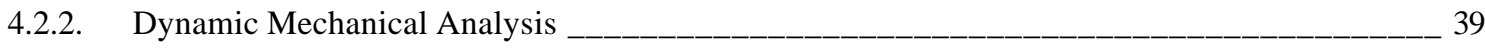

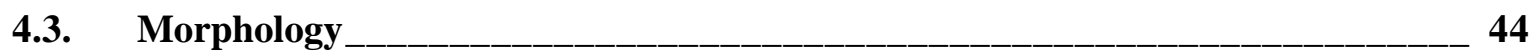

4.3.1. Transmission Electron Microscopy

4.3.2. Scanning Electron Microscopy

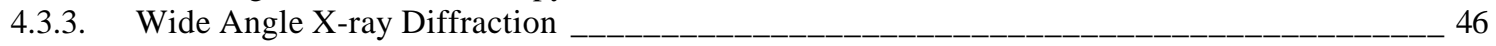

5. Conclusions _ 50

6. $\quad$ Future Work $\quad 52$

7. References__ 54 


\section{LIST OF TABLES}

TABLE 4.1. Percent Crystallinity, Onset Temperature, and Peak Melting Temperature 33

TABLE 4.2. Summary of mechanical properties for PP and composite samples as a function of nanotube concentration and fiber draw ratio. 39

TABLE 4.3. Herman's Orientation Factors. 48

TABLE 4.4. $\Delta P_{2}$ Values 49 


\section{LIST OF FIGURES}

FIGURE 2.1. Tensile strength comparison of common engineering materials. ${ }^{10}$ 5

FIGURE 2.2. Schematic of a (a) single-wall and (b) multi-wall nanotube. 6

FIGURE 2.3. Schematic of nanotube morphologies ((a) armchair, (b) zig-zag, (c) chiral). ${ }^{12}$

FIGURE 3.1. Schematic of winding apparatus (gray arrow: melt drawing pathway, black arrows: melt/solid drawing pathway).

FIGURE 4.1. TGA plot of a PP/3 wt \% MWNT sample. 31

FIGURE 4.2. TGA Plot of $100 \%$ PP sample and 3 wt \% MWNT sample. 32

FIGURE 4.3. DSC Melting Peaks for (a) $0 w t \%$, (b) 1 wt \%, and (c) $3 w t \%$ MWNTs in PP 33

FIGURE 4.4. Stress-strain curves for 12:1 melt drawn fibers (diamond: PP, square: PP/0.25, triangle: $P P / 0.5, x: P P / 1$, *: $P P / 3$ ). 34

FIGURE 4.5. (a) Tensile Toughness (MJ/m3), (b) Modulus (MPa), and (c) Yield Stress (MPa) as a function of nanotube loading in PP for several draw ratios (white: no draw, black bar: 12:1 melt drawn, vertical stripe: 23:1 melt/solid drawn, horizontal stripe: 24:1 melt/solid drawn) 36

FIGURE 4.6. Storage modulus, $G^{\prime}$, in $\mathrm{Pa}$ as a function of frequency, $\omega$ in $\mathrm{rad} / \mathrm{s}$ and temperature (diamond: $30^{\circ} \mathrm{C}$, square: $50^{\circ} \mathrm{C}$, triangle: $70^{\circ} \mathrm{C}, \mathrm{x}: 90^{\circ} \mathrm{C}$, *: $110^{\circ} \mathrm{C},-: 130^{\circ} \mathrm{C},+: 150^{\circ} \mathrm{C}$ ) for $0.25 \mathrm{wt} \% \mathrm{MWNTs}$ in PP (12:1 draw ratio) 40

FIGURE 4.7. Master curve for the 0.25 wt \% MWNT sample melt drawn fiber (12:1 draw ratio). 41

FIGURE 4.8. Shift factor as a function of temperature for 0.25 wt \% MWNTs in PP (12:1 draw ratio) with Arrhenius model. 42

FIGURE 4.9. Activation energy of fibers with 12:1 draw ratio. 43

FIGURE 4.10. Schematic of fiber orientation for electron microscopy images. 44

FIGURE 4.11. TEM Images of 3 wt \% MWNT in PP ((a) unoriented, (b) oriented, 12:1 draw ratio). 45

FIGURE 4.12. SEM Images of 3 wt \% MWNT in PP ((a) unoriented, (b) oriented, 12:1 draw ratio). 46

FIGURE 4.13. WAXD Patterns for (a) 0 wt \% and (b) 3 wt \% MWNTs in PP with 12:1 draw ratio. 47 


\section{MORPHOLOGICAL AND MECHANICAL PROPERTIES OF CARBON NANOTUBE/POLYMER COMPOSITES VIA MELT COMPOUNDING}

\section{INTRODUCTION}

\subsection{Background}

Polymer/carbon nanotube composites have the potential to offer a vast improvement over current materials available today. Research scientists believe that the excellent physical, thermal and electrical properties of the nanotubes can be realized at the macroscale by incorporating them into polymer matrices. Sucessful fabrication of such nanocomposites will lead to stronger and more conductive materials for advanced application (such as military and space). Examples include intelligent sensory materials in fabrics and films and strong, tough fibers for impact resistance.

The amount of research devoted to carbon nanotubes has grown significantly since Iijima's discovery of them in $1991^{1}$. Theoretical calculations and preliminary experimentation have shown carbon nanotubes have excellent mechanical properties, electrical conductivity $(5.1 \mathrm{x}$ $\left.10^{-6}-5.8 \Omega \mathrm{cm}\right)^{2}$, and thermal conductivity $(1750-5800 \mathrm{~W} / \mathrm{m} \mathrm{K})^{3}$. Treacy et al. ${ }^{4}$ found the Young's modulus of individual nanotubes to be in the range of $1 \mathrm{TPa}$ using intrinsic thermal vibrations. Although, carbon nanotubes show exceptional properties on the nanoscale, the difficulty lies in creating a material that exhibits carbon nanotube properties on the macroscale. Incorporating the nanotubes as filler into polymer matrices is the most common 
method currently explored. Similar to other composites made from chopped fiber in a polymer matrix, filler dispersion and orientation are essential to achieve optimal property improvements. Gelation/Crystallization, ${ }^{5}$ nanotube surface modification, ${ }^{6}$ and melt compounding $^{7,8}$ have demonstrated improved nanotube dispersion in a polymer matrix. Furthermore, research has shown improved mechanical properties via nanotube orientation by melt drawing after melt compounding in a poly(methyl methacrylate) (PMMA) matrix with low levels $(\sim 1 \mathrm{wt} \%)$ of MWNTs. ${ }^{8}$

\subsection{Challenges}

To achieve optimal property enhancement in any polymer matrix/particle filler composite system two essential parameters, filler dispersion and orientation, are vital. Carbon nanotubes, in both the single- and multi-wall form, agglomerate due to strong van der Waals forces and a high relative surface area. Due to this agglomeration, achieving homogenous nanotube dispersion throughout the polymer matrix is one of the biggest challenges to date. Furthermore, achieving nanotube orientation (to further enhance strength and toughness) is challenging due to the size scale of the particles. Finally, the addition of nanotubes could lead to pronounced viscosity increases during melt processing. However, at low loading levels it is not expected to cause large enough viscosity increases to affect the composite processability. 


\subsection{Objective}

The project objectives are to quantify the effect nanotube dispersion and orientation has on the mechanical properties and characterize the morphology of the nanocomposite. The primary objective is to investigate and optimize the effect of nanotube concentration on the mechanical properties of the composite fiber. Furthermore, characterization of the composite fiber morphology will be investigated in a qualitative and quantative manner to ascertain the structure-property relationship of this system.

The specific objectives of this project are as follows.

- To achieve nanotube dispersion and orientation within a polypropylene matrix

- To characterize composite mechanical properties as a function of nanotube concentration and orientation

- To characterize composite morphology as a function of nanotube concentration and orientation 


\section{LITERATURE REVIEW}

\subsection{Carbon Nanotubes}

\subsubsection{Discovery}

In 1991, Japanese microscopist, Sumio Iijima observed graphitic carbon needles, ranging from 4 to $30 \mathrm{~nm}$ in diameter and up to $1 \mathrm{~mm}$ in length, as byproducts of the arc-discharge evaporation of carbon in an argon environment. ${ }^{1}$ Further research by Iijima demonstrated the ability to produce single-sheet tubules with diameters ranging from $0.7 \mathrm{~nm}$ to $1.6 \mathrm{~nm} .{ }^{9}$ However, no tubules were produced when argon, iron, or methane were absent from the experimental environment. Based on the very high aspect ratio of these nanotubes, research scientist expected the material to be stronger than current materials. Therefore, a group of scientist used the vibration of the nanotubes as a function of temperature to calculate a Young's modulus of $1 \mathrm{TPa}^{4}$ Such high strength as compared to other materials, shown in Figure 2.1 below, has led to an increased interest in carbon nanotube materials. However, many research groups have proposed different results using carbon nanotubes. 
Tensile Strength (GPa)

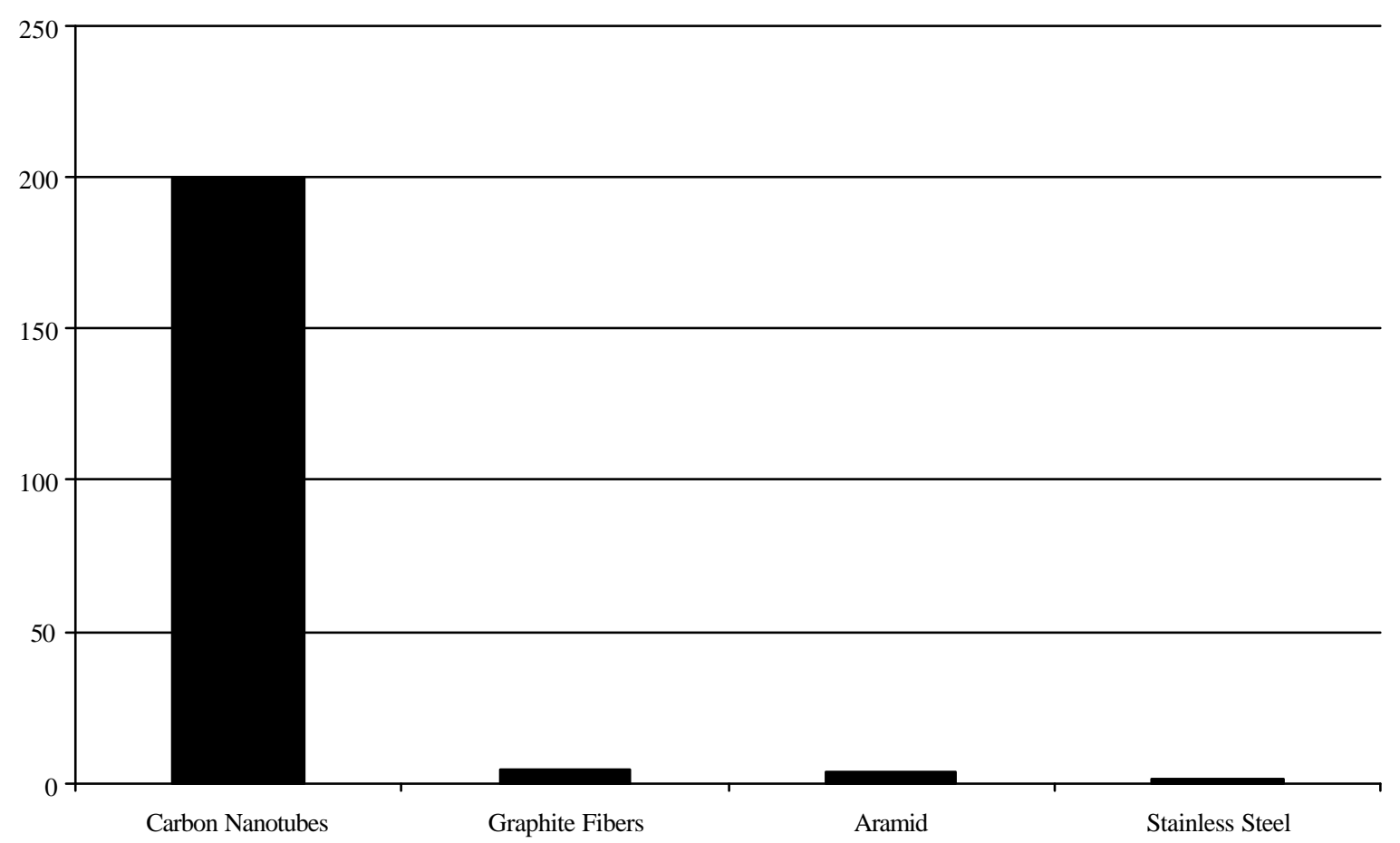

FIGURE 2.1. Tensile strength comparison of common engineering materials. ${ }^{10}$

Nanotubes are sythesized in two structural forms, single-wall and multi-wall (as shown in Figure 2.2). The first tubules Iijima discovered exhibited the multi-wall structure of concentric nanotubes forming one tube defining a multi-wall nanotube (MWNT). ${ }^{1}$ After further work, he observed a single-shell structure believed to be the precursor to the MWNTs. ${ }^{9}$ The single graphitic sheet rolled into a tube with a cap at either end and diameter around $1 \mathrm{~nm}$ was defined as a single-wall nanotube (SWNT). ${ }^{11}$ Additionally, nanotubes are described using one of three morphologies: armchair, zigzag, and chiral (as shown in Figure 2.3). The packing of the carbon hexagons in the graphitic sheets define a chiral vector and angle. The indices of the vector determine the morphology of the nanotube. Variations in the nanotube morphology can lead to changes in the properties of the nanotube. For instance, 
the electronic properties of an armchair nanotube are metallic; however, the electronic properties of zigzag and chiral nanotubes can be either metallic or semi-conducting. The behavior is determined based on a mathematical model developed using the chiral vector indices. $^{10}$

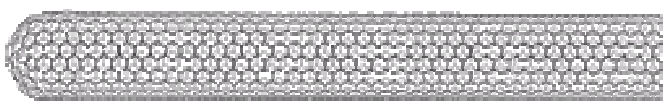

(a)

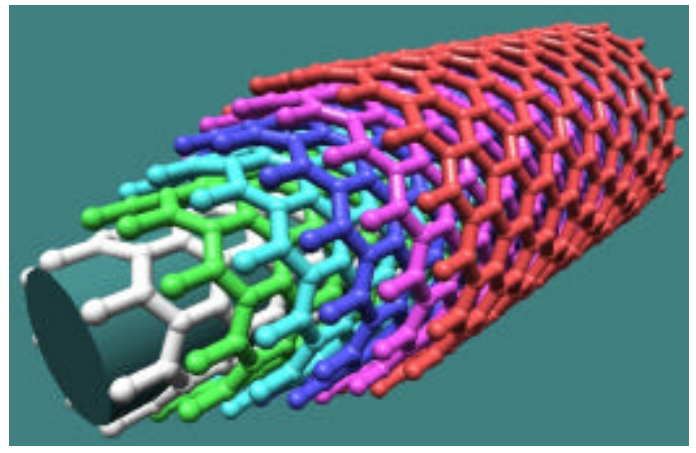

(b)

FIGURE 2.2. Schematic of a (a) single-wall and (b) multi-wall nanotube. 

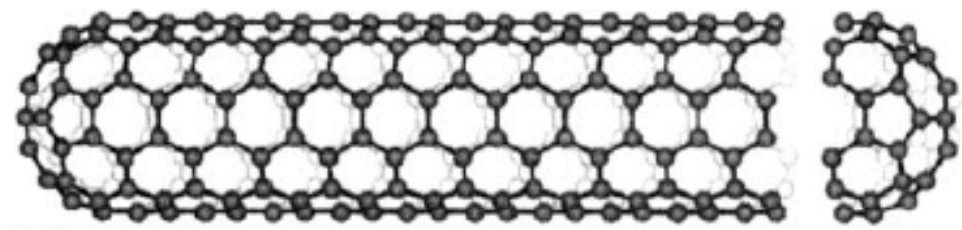

(a)
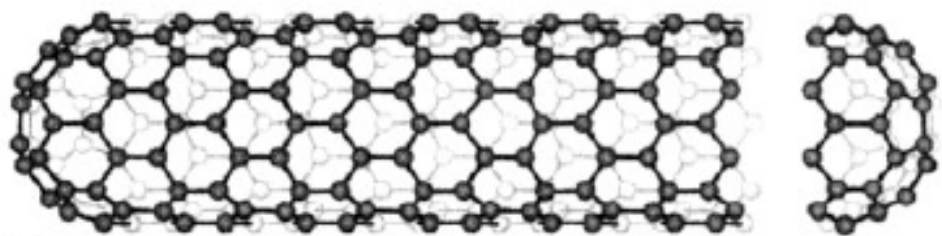

(b)

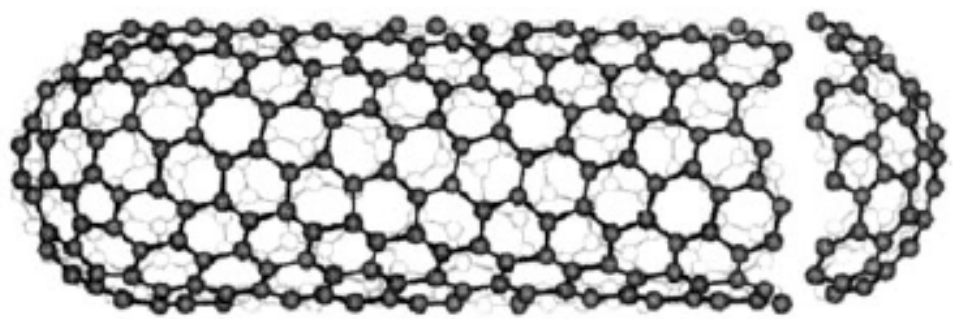

(c)

FIGURE 2.3. Schematic of nanotube morphologies ((a) armchair, (b) zig-zag, (c) chiral). ${ }^{12}$

\subsubsection{Production Methods}

Since the discovery of the carbon nanotube, research devoted to nanotube related materials has increased dramatically. The increase began with the investigation of production methods for both MWNTs and SWNTs. The current methods of manufacturing nanotubes include direct-current arc discharge, laser ablation, thermal and plasma enhanced chemical vaporgrowth depositions (CVD), and self-assembly of single crystals of SWNTs. ${ }^{10}$ Each method has advantages and disadvantages. Direct-arc discharge and laser ablation require addition of a small amount of metal catalyst and very high temperature. The products of such methods are normally tangled and poorly oriented. However, laser ablation has become the common method for producing SWNTs. ${ }^{13}$ CVD produces nanotubes from the decomposition of a 
continuously supplied carbon containing gas onto a substrate. Due to the continuous supply of the gas and the fact that a catalyst is not needed, high-purity nanotubes can be produced on a large volume scale. Producing the nanotubes in an ordered array with controlled length and diameter can be achieved through CVD methods as well. Furthermore, plasma enhanced chemical vapor deposition (PECVD) results in further nanotube uniformity within the array. ${ }^{14}$ More recently a team led by Schlittler has developed a self-assembly method for making an ordered array of nanotubes with identical geometry and high purity. ${ }^{15}$

\subsubsection{Properties}

Due to the size scale of nanotubes, directly measuring the properties of interest (such as mechanical properties and thermal/electrical conductivity is difficult using conventional experimental methods. Therefore, mathematical modeling primarily has been used to obtain property values. These models are often derived based on models used for similar structures, such as graphite, with modifications to account for the tubular shape. For example, molecular dynamics, empirical potentials and first-principles total-energy, continuum shell, and empirical lattice model were used to describe the elastic properties of nanotubes. ${ }^{16-18}$ The empirical lattice models, previously used to calculate the elastic properties of graphite,

led to tensile modulus values in the range of $1 \mathrm{TPa}$ for multi- and single-wall nanotubes. ${ }^{16}$ These values compared well with diamond and out-performed conventional carbon fibers.

These exceptionally high theoretical values led to increased interest in nanotubes as both structural and conductive materials and have therefore led to the development of techniques 
to measure nanotube properties experimentally. Common methods to measure the elastic properties of individual nanotubes include micro-Raman spectroscopy, ${ }^{19}$ thermal oscillations by transmission electron microscopy, ${ }^{4,20}$ and application of a force to a nanotube rope suspened across a pit using an atomic force microscope cantilever. ${ }^{21,22}$ Other groups measured the properties of a rope and obtained an average value for each tube based on the number of nanotubes in the rope. ${ }^{23,24}$ The experimental values measured ranged from significantly below theoretical values to values in agreement with the models. These methods have produced tensile modulus and strength values for single- and multi-wall nanotubes ranging from $270 \mathrm{GPa}$ to $1 \mathrm{TPa}$ and $11 \mathrm{GPa}$ to $200 \mathrm{GPa}$ respectively. ${ }^{10}$

In addition to the mechanical properties, research has been performed to determine the electrical and thermal conductivity of nanotubes. In a similar fashion, modeling has been used to determine the conductivity via the structure of the nanotubes as compared with graphite. Much of the theoretical work found that conductivity depends on the small structural variations in the nanotubes. ${ }^{2}$ For example Berber et al. found unusually high thermal conductance of $6600 \mathrm{~W} / \mathrm{m} \mathrm{K}$ at room temperature for a particular nanotube structure using nonequilibrium and equilibrium molecular dynamics. ${ }^{25}$ However, Hone et al. reported slightly lower values in the range of $1750-5800 \mathrm{~W} / \mathrm{m} \mathrm{K}$ for the room temperature of a single nanotube rope by comparing the temperature drop across a constantan rod of known thermal conductance to a nanotube mat sample in series with the rod. ${ }^{3}$ In a similar fashion, the static electrical conductive and superconductive nature of nanotubes was modeled based on the conductivity of the graphite sheet structure. ${ }^{26}$ The scale of the individual nanotubes 
eliminated many of the conventional methods used to measure conductivity. Experimental four-probe measurements of individual nanotubes showed resistivities in the range of $5.1 \mathrm{x}$ $10^{-6}-5.8 \Omega \mathrm{cm}$ (or conductivities ranging from 0.17 to $196,078 \mathrm{~S} / \mathrm{cm}$ ). ${ }^{2}$ As with the mechanical properties, the variation in the conductivities lies in the procedures used and the differences in the nanotube structure.

\subsection{From Nanoscale to Macroscale}

After quantifying the remarkable properties of carbon nanotubes, the challenge has become translating these properties from nanoscale to macroscale. Currently many methods of producing macroscale nanotube materials have been investigated. Some methods attempt to form fibers from nanotubes alone; whereas, other procedures use a matrix to support the nanotubes. Without a support medium, research teams expect to achieve property values closer to the values of the individual nanotubes. However, the use of a matrix or binder often makes production of macroscale materials more feasible. Forming fibers directly from nanotube production methods, such as arc discharge ${ }^{27}$ and chemical vapor deposition, ${ }^{28}$ has been investigated. Furthermore, research has shown the ability to create nanotube yarns by twisting them together as they are pulled out of a nanotube forest. ${ }^{29}$ Other studies have proposed using super-acid solutions as a medium to support the fiber through a conventional spinning process followed by the removal of the medium. ${ }^{30,31}$ However, the most common method has been to incorporate them in a polymer matrix as a reinforcing material. The combined polymer/nanotube structure is often referred to as a nanocomposite. Research has proposed that the nanotubes will provide load transfer in the same way chopped glass fibers 
do in conventional composite systems. The property response of polymer/nanotube composites have varied from no change $e^{32,33}$ to moderate increases in mechanical properties (25\%-50\% modulus increase; $80 \%-150 \%$ toughness increase), ${ }^{34}$ electrical properties (with a perculation threshold of $0.0025 \mathrm{wt}-\%$; conductivity $2 \mathrm{~S} / \mathrm{m}),{ }^{34}$ and thermal properties (125\% increase at room temperature). ${ }^{12}$ However, optimal property improvements have not been achieved due to deficiencies in nanotube dispersion and alignment.

\subsection{Polymer/Nanotube Composites}

\subsubsection{Filler Dispersion and Orientation}

Two essential components for optimal reinforcement in chopped fiber (and nanotube) reinforced composite systems are filler dispersion and orientation. Consistent dispersion of the reinforcing material throughout the matrix leads to consistent load transfer from matrix to particle. Moreover, it can assist with the realization of a network for conductivity of electrical and thermal energy. Similarly, orientation in the direction of applied forces allows for greater load transfer. If the particle is oriented in a direction other than the direction of the applied force, the full potential of the particle cannot be realized. In addition, having all the particles oriented in the same direction allows for easier transfer of energy (electrical or thermal). Achieving consistent dispersion and orientation will allow for optimal property improvements.

Several ways to achieve nanotube dispersion include gelation/crystallization, ${ }^{5}$ nanotube surface modification, ${ }^{6,35-37}$ and melt compounding. ${ }^{8,38-42}$ In gelation/crystallization 
experiments, the nanotubes were dissolved in a solvent, polymer solution was added, a gel was formed, the gel was formed into a film, and finally the solvent was evaporated. ${ }^{5}$ Nanotube surface modifications used plasma treatment or chemical oxidation to attach functional groups. These groups allowed the nanotubes to bond better to the matrix and overcome the van der Waals interactions between nanotubes. ${ }^{6}$ Finally, melt compounding involves creating a preblend by dry mixing polymer powder with the nanotube powder. The preblend is fed into an extruder allowing for control of shear, temperature, and residence time. After the residence time, the material is extruded in the film or fiber form. ${ }^{8}$

Good dispersion alone has shown moderate property improvements, but nanotube alignment, or orientation, has led to further improvements. Using melt compounding followed by melt drawing, has shown a significant increase in mechanical properties. ${ }^{8}$ Transmission and scanning electron microscopy has shown good dispersion and orientation using such methodology. ${ }^{8,38}$ These improvements have been shown to increase until and optimal loading level and then decrease above this concentration. ${ }^{8,43}$ In addition to mechanical drawing, the inherent conductive nature of carbon nanotubes has been utilized to induce alignment. For example, the application of a magnetic field to a nanocomposite sample during or after processing has shown nanotube alignment. ${ }^{44,45}$ Again, the optimal properties, as predicted by such models as Halpin-Tsai, have not been achieved due to poor interfacial bonding, variations in nanotube structure, and nanotube properties variation. 


\subsubsection{Single- or Multi-wall Nanotubes}

Another concern, when producing composites using carbon nanotubes, has been whether to use single- or multi-wall nanotubes. Research has shown that each type has advantages and disadvantages. Single-wall nanotubes tend to agglomerate more easily due to the strong attractive forces. The size difference (i.e. greater surface area) leads to the problem of increased agglomeration for single-wall nanotubes. Multi-wall nanotubes have been found to demonstrate lower mechanical, electrical and thermal properties due to the ability of the concentric nanotubes to slide past each other. Single-wall nanotubes often require more specialization to produce than multi-wall. Therefore, the cost of single-wall nanotubes tends to be greater than multi-wall nanotubes. Due to the inherent tube within a tube structure, the multi-wall nanotubes tend to have a larger diameter $(10 \mathrm{~s} \mathrm{~nm})$ as compared with single-wall nanotubes $(\sim 1 \mathrm{~nm})$. However, improvements in nanotube fabrication have led to multi-wall nanotubes with more precise, smaller diameters. This could lead the nanotubes with improved properties over larger diameter multi-wall nanotubes and less agglomeration than the single-wall nanotubes.

\subsubsection{Matrix Material}

Most researchers utilize thermoplastic polymers for their ease of use and processibility. This allows fibers or films to be made and easily melt processed into molded parts. Research has been performed using both amorphous and semicyrstalline polymers with success. The nanotubes have been shown to toughen and stiffen amorphous brittle materials, such a poly(methyl methacrylate). ${ }^{8,39,46}$ In addition the toughening and stiffening effects, 
morphological changes are the subject of discussion for semicrystalline polymers, such as polypropylene. Research literature has suggested that nanotubes act as nucleating agents in these materials leading to new crystallographic morphologies and ultimately increased strength. ${ }^{38,47-49}$ Many other thermoplastic polymers, both amorphous and semicrystalline, have been researched as matrix materials. However, polypropylene has been shown to be one of the most popular polymers of interest in polymer/nanotube composite materials.

Although, most polymer/nanotube composite research has utilized thermoplastic matrices, some research has been conducted with thermoset matrices. ${ }^{50-59}$ The thermosetting polymers are converted from liquid resin to hard rigid solids by chemical cross-linking often at an elevated cure temperature. ${ }^{60}$ Due to the chemical cross-linking, thermosetting materials can not be reprocessed. Furthermore, the materials tend to be more brittle than thermoplastic matrices. $^{60}$ Research has been done to study mechanical, ${ }^{50,52,57-59}$ thermal, ${ }^{57}$ and electrical $5^{51,53,55,59}$ properties of thermosetting polymer/nanotube composites with various

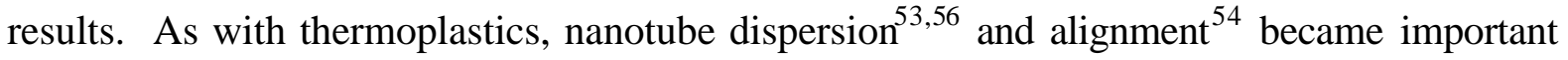
factors in achieving property improvements. While various thermosetting polymers have be used in the research, epoxies have been the most commonly utilized materials.

\subsubsection{Polypropylene/Nanotube Composites}

\subsubsection{Polypropylene}

Polypropylene is an inexpensive commodity material currently used in many research facets. The most common type used in films and fibers is the isotactic form, due to the regular 
structure allowing good crystal packing. Extensive structure-property relationships have been developed for polypropylene. ${ }^{61-63}$ For example, polypropylene demonstrates polymorphism with $\alpha$ and $\beta$ crystal forms. ${ }^{63}$ Furthermore, methods of processing polypropylene into fibers, films, or other forms have been extensively studied. Melting processing polypropylene into fibers for applications, such as textile fibers, is the most common method studied. The availability, ease of use, and ease of manufacture has led to wide use of polypropylene for many research studies.

\subsubsection{Crystallization}

Studies have proposed that nanotubes could nucleate crystallization, increase crystallization rates, change the crystal form, and alter the overall percent crystallinity. Such changes have been proposed as possible mechanisms for property improvements, such as modulus. In such studies both single- ${ }^{38,48,64,65}$ and multi-wall ${ }^{47,49,66}$ nanotubes have been used to study such crystallization behavior.

For SWNTs, the crystallization temperature, $\mathrm{T}_{c}$, increases with increased loading levels of 1$20 \%$ SWNTs. ${ }^{38,48,64,65}$ The studies proposed the increase in $\mathrm{T}_{\mathrm{c}}$ suggests the nanotubes

nucleate crystal growth. ${ }^{38,64,65}$ Furthermore, optical microscopy shows large well defined grains in pure polypropylene but smaller grains in polypropylene/nanotube composites. ${ }^{38,64,65}$ These smaller grains coupled with shifts seen by Raman and Infrared Spectroscopy further indicates nucleation via nanotube addition. ${ }^{64,65}$ Nucleating agents can lead to the formation of $\beta$ crystals in polypropylene. ${ }^{38}$ However, wide angle X-ray diffraction showed only the 
common $\alpha$ polypropylene crystals. ${ }^{38}$ Further crystallization kinetics experiments showed no changes in the Avarami exponent at constant loading level. ${ }^{38}$ However, changing the loading level changes the Avarami exponent. ${ }^{48}$ Further crystallization experiments showed the crystallization rate increased with the addition of nanotubes but did not increase with increased loading levels. ${ }^{38,48}$ The addition of single-wall nanotubes to polypropylene increases $T_{c}$, nucleates $\alpha$ crystal growth, changes the Avarami exponent with increasing loading, and increases the rate of crystallization.

Similar to the case of single-wall nanotubes, multi-wall nanotubes demonstrated an increase in the crystallization temperature, $\mathrm{T}_{\mathrm{c}}{ }^{47,49,66}$ Additionally, no changes in the overall percent crystallinity were observed with the multi-wall nanotube reinforced composites. ${ }^{47,49}$ The combination of increased $T_{c}$ and no change in the overall percent crystallinity led to the conclusion that the nanotubes are nucleating more smaller polypropylene crystals at higher termperatures. ${ }^{47,49,66}$ Bright field optical microscopy images showed further evidence of nanotubes acting as nucleation sites. ${ }^{49}$ These images showed crystal lamella growing off the nanotubes perpendicular to the main polymer chain axis. ${ }^{49}$ Crystallization kinetics $^{4}$ experiments also showed in increase in the rate of crystallization using Avarami's equation. $^{49,66}$ In contrast to single-wall nanotubes, the addition of multi-wall nanotubes led to a small decrease in the Avarami exponent. ${ }^{49}$ Furthermore, Ozama's $m$ also decreased with the addition of multi-wall nanotubes suggesting a change in the crystal dimensionality. ${ }^{47}$ Similar to single-wall nanotubes, multi-wall nanotubes increased the crystallization temperature, increased the crystallization rate, acted as nucleation sites, and did not increase 
the overall crystallinity. However, in contrast, multi-wall nanotubes demonstrated a change in the dimensionality of the crystal growth.

\subsubsection{Morphology}

Closely related to the effects nanotubes have on the crystallinity of a semicrystalline polymer is the morphology of the composite. Much work has been done to determine how the addition of nanotubes could affect the polymer morphology. In the case of polypropylene, the neat polymer exhibits a spherulitic morphology. ${ }^{47}$ Scanning electron microscopy depicts the morphology as large circular grains growing and impinging on each other. ${ }^{47}$ Using electron microscopy researchers have studied the effects nanotubes have on this morphology. Different effects are reported for single- ${ }^{38,65}$ and multi-wall ${ }^{47,49,67}$ nanotubes, similar to those seen when looking at crystallization.

Research has shown the addition of single-wall nanotubes maintains the general spherulitic morphology at loading levels of $1-20 \%$ SWNTs. ${ }^{38,65}$ Optical micrographs show large spherulites impinging on each other with neat polypropylene. ${ }^{38,65}$ In contrast, a large quantity of smaller spherulites are seen in the micrographs of the nanocomposite samples. ${ }^{38,65}$ However, as the loading level of nanotubes increases to $15 \%$ and greater, aggregation of the nanotubes begins to occur. ${ }^{65}$ The aggregates show up as self assembled bundles in the optical micrographs. ${ }^{65}$ Furthermore, Raman spectroscopy of $0,5,10,15$, and $20 \%$ samples showed trends in the D-band graphitic structure peak. ${ }^{65}$ The relative area under the peak increased significantly until $15 \%$ nanotubes at which point the increase slowed. ${ }^{65}$ 
Additionally, the peak width increased until $15 \%$ and stopped. ${ }^{65}$ Finally, the position shifted until $15 \%$ and then returned. ${ }^{65}$ From these results, the researchers concluded that until $15 \%$, the polymer was intercalated into the nanotubes. ${ }^{65}$ Above this point, the nanotubes became saturated and did not allow more polymer to penetrate into the nanotubes. ${ }^{65}$ At low loading levels, polymer intercalates single-wall nanotubes leading to crystal nucleation and a large quantity of smaller grains seen in optical micrographs. Above the optimal level (15\%), the nanotubes do not intercalate and instead aggregate into self assembled bundles. As discussed above, this is supported by the constant Avarami exponent denoting three dimensional crystal growth at low concentrations.

In contrast, multi-wall nanotubes were shown to have a lower value for Ozama's $m$, denoting change from three dimensional to two dimensional crystal growth. ${ }^{47}$ Optical micrographs of polypropylene/multi-wall nanotubes exhibited fibrillar morphology. ${ }^{47}$ The normal spherulitic morphology of polypropylene has three dimensional growth; whereas, fibrillar morphology exhibits two dimensional growth. Although the morphology changed, the sample still appeared homogenous throughout revealing good dispersion. ${ }^{47}$ In another study using highly oriented nanocomposite films and fibers, a different morphology was observed. ${ }^{49}$ Due to the orientation of the molecular chains imparted by drawing the sample, the multi-wall nanotubes were also oriented in the direction of the drawing. ${ }^{49}$ However, the crystal lamella were seen growing perpendicular to the molecular axis and the oriented nanotubes. ${ }^{49}$ Finally, another study looked closely at the interface between chlorinated-polypropylene and multiwall nanotubes. ${ }^{67}$ Close to the surface of the nanotubes, a crystalline layer was observed and 
measured. ${ }^{67}$ The study suggested that this layer increased polymer/nanotube adhesion and ultimately led to property improvements, such as increased toughness and modulus. ${ }^{67}$ As with crystallization, morphological changes have been proposed as possible factors in improved mechanical properties of polymer/nanotube composite system.

\subsubsection{Mechanical Properties}

Research has shown mechanical property improvements with the addition of both single- and multi-wall nanotubes to polypropylene. Additionally, dispersion of the nanotubes performs a large role in the property improvements. One study showed the additional of $1 \mathrm{wt} \%$ singlewall nanotubes via melt blending did not significantly improve these properties. ${ }^{38}$ In the study, scanning electron microscopy images showed micrometer scale aggregates and nanotube ropes within the sample. ${ }^{38}$ Some research has suggested the aggregates could act as stress concentrators inhibiting property improvement. However, from the slight increases, the aggregates either were not big enough to create stress concentrations, or the strength of the ropes was greater than the losses from the stress concentrations. ${ }^{38}$ The research concluded better nanotube dispersion would lead to more rope, less aggregates, and ultimately significant mechanical property improvements. ${ }^{38}$

In another study, significant property improvements were observed when adding single-wall nanotubes to polypropylene. ${ }^{68}$ The nanotubes were first dispersed in the polymer using solution processing. ${ }^{68}$ After removing the solvent, the fibers were melt spun and postdrawn for improved dispersion and orientation. ${ }^{68}$ The addition of 0.5 and 1 wt $\%$ demonstrated 
increasing tensile strength and modulus values. ${ }^{68}$ At 1 wt $\%$, the tensile strength and modulus were $40 \%$ and $55 \%$ higher than the neat polypropylene fibers. ${ }^{68}$ However, additions of 1.5 and 2 wt $\%$ made spinning the fibers difficult and led to lower mechanical properties. ${ }^{68}$

A similar maximum in mechanical properties as a function of nanotube loading was also noted in another study in both conventional tensile experiments and dynamic mechanical analysis. $^{69}$ The study looked at the properties of both as-spun fiber and postdrawn polypropylene/single-wall nanotube fibers. Additionally, the studies investigated any differences in low melt flow rate and high melt flow rate polypropylene. The basic tensile qualitative behavior of neat polypropylene (high initial modulus, sharp yield, and stretching to very long elongations) was observed in the as-spun nanocomposites. However, the nanocomposites exhibited lower elongation to break values. Increasing tensile strength was noted for the low melt flow rate samples and the opposite for the high melt flow rate samples. Furthermore, the postdrawn low flow rate samples increased in tensile strength up to $1 \%$ and then decreased. The higher concentrations caused the fibers to be come brittle and difficult to draw. All of the high melt flow rate samples exhibited decreasing ultimate tensile strength. The dynamic mechanical analysis produced results similar to the conventional tensile tests. Within temperature limits, the storage modulus, E', increased with increasing nanotube additions. At the higher temperatures, E' of the postdrawn samples began to decrease. The concentration of $1 \%$ was found to be the optimal value to increase E'. Moreover, as evidenced by the tensile test, the postdrawing process created a far stiffer 
material. In contrast, the loss modulus, E", show little to no discernable trend as related to polypropylene grade or nanotube concentration.

Research of polypropylene/multi-wall carbon nanotubes has been preformed to a lesser extent than single-wall nanotubes. In one study, functionalized nanotubes were added to chlorinated polypropylene to create composite films. ${ }^{67}$ The study noted an upward shift in the yield point on the stress-strain curve and consequently increased yield strength. ${ }^{67}$ Additionally, the Young's modulus, ultimate tensile strength, and toughness increased with increasing nanotube volume fraction by a factor of $3.1,3.9$, and 4.4 , respectively. ${ }^{67}$ From the data and previously derived composite models, mathematical models based on volume fraction were developed for the Young's modulus and composite strength. ${ }^{67}$ In another study, polypropylene/multi-wall nanotube powder was created using a pan milling process. ${ }^{66}$ The pan milling of the neat polypropylene reduced the elongation to break significantly. ${ }^{66}$ However, the addition of nanotubes increased the elongation to break (over pan-milled polypropylene) through crystal structure changes and induced polypropylene orientation. ${ }^{66}$ Again an optimal 1\% nanotube loading exhibited increased Young's modulus and yield strength. ${ }^{66}$ The pan milling allows for better dispersion, reduces the number of defects, curvature, and entanglements, and enhances the polymer/nanotube adhesion. ${ }^{66}$

\subsection{Conclusion}

Carbon nanotubes and polymer/nanotube composites are a fast growing area of materials research and development. The theoretical and experimental mechanical, electrical, and 
thermal properties of individual nanotubes are exceptionally high. Therefore, tremendous opportunity to transfer the nanoscale properties to macroscale materials exists. To create such macroscale materials, many issues surrounding the incorporation of nanotubes into polymer matrices, strategies for property improvements, and the mechanisms responsible for those property improvements still remain. Since only moderate success has been made over the last ten to fifteen years, researchers continue to investigate materials such as polymer/nanotube composites to achieve properties of nanotubes on the macroscale. 


\section{EXPERIMENTAL}

\subsection{Materials}

Exxon Mobil Type 3155 Polypropylene (PP) with a melt flow rate of $36 \mathrm{~g} / 10 \mathrm{~min}$, density of $0.9 \mathrm{~g} / \mathrm{cm}^{3}$, and molecular weight distribution of 2.8 , was utilized as the matrix. Multi-wall Carbon Nanotubes (MWNT) produced by chemical vapor deposition and purchased from Nanolab in Brighton, MA were used as the filler. These nanotubes had purity greater than $95 \%$, diameter of $20-50 \mathrm{~nm}$, and length of 5-20 $\mu \mathrm{m}$.

\subsection{Techniques}

\subsubsection{Composite Preparation}

The PP pellets were ground into a powder using a SPEX ${ }^{\circledR}$ CertiPrep Freezer Mill. The pellets were precooled for 5 minutes followed by three- 2 minute grinding cycles at $10 \mathrm{~Hz}$. Between each cycle the sample was cooled for a 1 minute interval. Nanocomposites were created by dry blending the PP powder with a given ratio of MWNTs $(0.25,0.50,1$, and $3 \mathrm{wt}$ $\%)$. The preblend was then fed into a Haake Mini-Lab twin screw extruder and processed for $10 \mathrm{~min}$ at $100 \mathrm{rpm}$ and $200{ }^{\circ} \mathrm{C}$. After 10 minutes, the composite was extruded through a 1.75-mm cylindrical die. Oriented samples were created using a specially designed winding apparatus with melt and solid drawing capabilities (see Figure 3.1). The winding apparatus consisted of three polypropylene rollers each driven by variable speed motors. The center to center distance for the first and and second rollers is 15 in, and for the second and third rollers is 24.75 in. Each motor achieved linear speeds on the outer roller surface of $45-450$ in/min. The rollers could be all controlled independently, all dependently, or the first roller 
independent of the second and third rollers. For melt drawing, the material exited the die passed around the first roller three times and was taken up on the third roller with the rollers at the same speed higher than the speed the material left the extruder. Using this procedure, melt drawn samples had a nominal draw ratio of 12:1. In coupled melt/solid drawing, the material exited the die at one speed, passed around the first roller at a slightly higher speed, passed around the second roller at a greater speed than the first roller, and finally was taken up on the third roller at the same speed of the second roller. Using this procedure, coupled melt/solid drawn samples had nominal draw ratios of 23:1 and 24:1. After extruding both oriented and unoriented samples, the mechanical and morphological properties were characterized using the techniques described in the following sections.

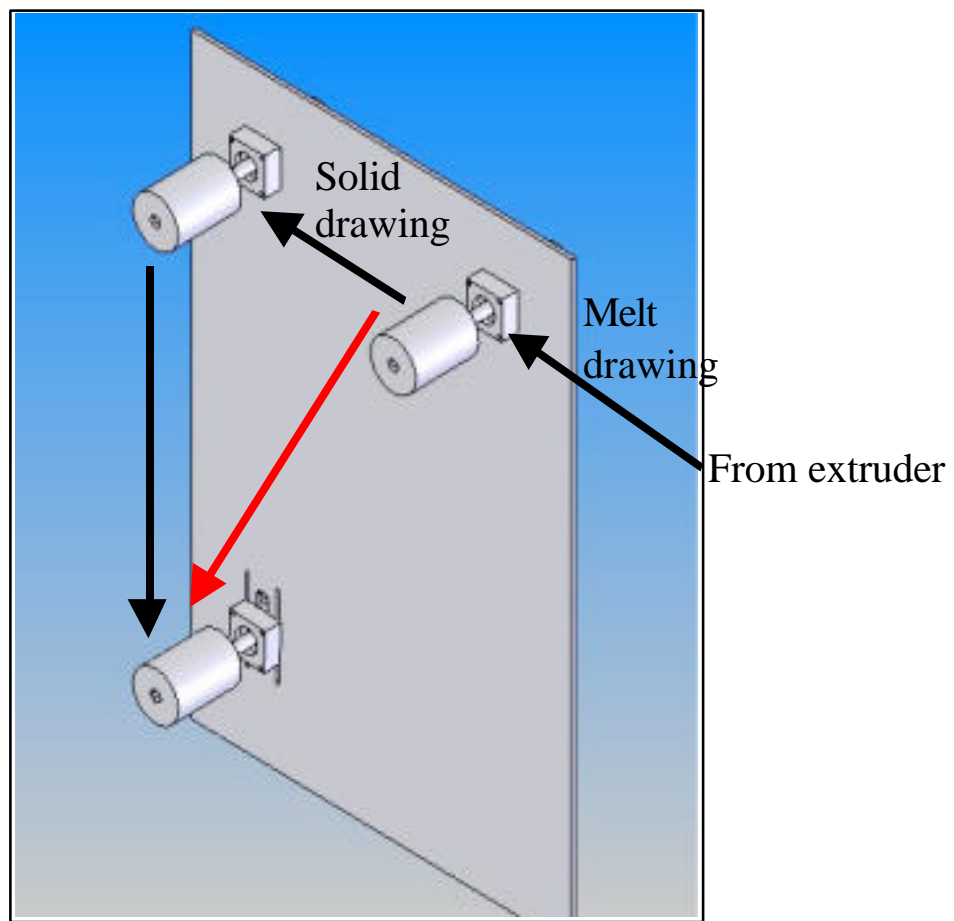

FIGURE 3.1. Schematic of winding apparatus (gray arrow: melt drawing pathway, black arrows: melt/solid drawing pathway). 


\subsubsection{Thermal Analysis}

\subsubsection{Thermal Gravimetric Analysis}

A Perkin Elmer Pyris 1 Thermal Gravimetric Analyzer (TGA) was used to determine the weight percent concentration of nanotubes in the composite samples. Approximately $20 \mathrm{mg}$ of each sample was heated from $25^{\circ} \mathrm{C}$ to $950^{\circ} \mathrm{C}$ at a rate of $20^{\circ} \mathrm{C} / \mathrm{min}$ in a nitrogen environment. As the sample is heated, the mass is measured as function of temperature. The mass retained is calculated by dividing the mass at the temperature of interest by the initial mass. The percent mass is plotted as a function of temperature and shows a plateau at about $500-600^{\circ} \mathrm{C}$, where the polymer has degraded. The percent mass at this plateau is hypothesized to be MWNTs since they do not degrade in nitrogen until temperatures above $1000^{\circ} \mathrm{C}$ (from discussion with David Carnahan, President of Nanolab).

\subsubsection{Differential Scanning Calorimetry}

Using a Perkin Elmer Diamond differential scanning calorimeter, the crystalline morphology of the composite samples was studied. Each sample was heated from $25^{\circ} \mathrm{C}$ to $200^{\circ} \mathrm{C}$ at a rate of $10^{\circ} \mathrm{C} / \mathrm{min}$ to observe the full thermogram. The thermograms were used to determine the onset melting temperature, peak melting temperature, peak area, and enthalpy of melting $(\Delta \mathrm{H})$. To achieve more accurate values for these temperatures, a straight baseline was drawn connecting each flat side of the melting peak. The shapes of the curves at different loading levels were evaluated qualitatively to determine changes crystal structure. Finally, the overall percent crystallinity was calculated by dividing the enthalpy of melting for the sample $(\Delta \mathrm{H})$ by the enthalpy of melting for $100 \%$ crystalline polypropylene $\left(\Delta \mathrm{H}_{\mathrm{f}}^{\mathrm{o}}=207.1 \mathrm{~J} / \mathrm{g}\right){ }^{62}$ 


\subsubsection{Mechanical Properties}

\subsubsection{Tensile}

Tensile tests were preformed to measure the tensile toughness $\left(\mathrm{MJ} / \mathrm{m}^{3}\right)$, modulus (MPa), and yield strength $(\mathrm{MPa})$ of the oriented and unoriented samples at each loading level. The tests were performed on an Instron ${ }^{\circledR}$ Model 5544 using the Bluehill ${ }^{\mathrm{TM}}$ Version 1.00 software package. Ten replicates of each sample were run to obtain average, standard deviation, and standard error values. Each experiment was conducted with a gauge length of $25.4 \mathrm{~mm}$, crosshead speed of $25.4 \mathrm{~mm} / \mathrm{min}$, and data acquisition rate of 50 points/second. To obtain the elastic modulus, a linear regression technique was utilized to define the slope of the stress-strain curve in the initial region before yield. The toughness was calculated using the product of the energy at break at $98 \%$ maximum load and the sample volume. The energy at break was defined as the area under the force-elongation curve up to the break point, which was defined as $98 \%$ of the maximum load. The volume was defined for a cyclinder with initial diameter, $\mathrm{d}$, and initial length, 1 , as follows:

$$
\mathrm{V}=\pi *\left(\mathrm{~d}^{2} / 4\right) * 1
$$

Therefore, the defined calculation for toughness equals the energy at break divided by the volume of the sample. The yield strength was calculated using the slope threshold algorithm from the BlueHill ${ }^{\circledR}$ software package. In the algorithm, the point where the slope of the stress/strain curve decreases to user selected percentage of the modulus slope. After experimenting with several different percentages, the value chosen was $2 \%$, because the marker placed on the stress-strain curve most closely approximated the appropriate location for a polymer system. 


\subsubsection{Dynamic Mechanical Analysis}

Dynamic mechanical analysis was used to investigate the viscoelastic properties of the sample. The Q800 Dynamic Mechanical Analyzer from TA Instruments was used for these experiments. The fiber clamp was used for the oriented samples, and the film clamp was used for the unoriented samples. The samples were run using a DMA Multi-Frequency Strain procedure with a temperature step and frequency sweep. All samples were cylindrical with length, 1 , and diameter, d. The temperature was stepped by $20^{\circ} \mathrm{C}$ from $30^{\circ} \mathrm{C}$ to $150^{\circ} \mathrm{C}$. The frequency sweep was $0.01-100 \mathrm{~Hz}$ on a logarithmic scale with 3 points per decade. Time-temperature superposition master curves were created by selecting a reference temperature in the middle of the experimental temperature range, $90^{\circ} \mathrm{C}$, and shifting the other curves it relation to the reference curve. The storage modulus, loss modulus, and $\tan \delta$ master curves were analyzed for trends as a function of nanotube loading. Additionally, the activation energy of the composite fibers was calculated using Arrhenius equation and was analyzed for trends as a function of nanotube loading.

\subsubsection{Morphology}

The morphology of the polypropylene/nanotube composite samples was observed both qualitatively and quantitatively. The orientation of the nanotubes was verified through transmission electron microscopy (TEM), scanning electron microscopy (SEM), and wide angle X-ray diffraction (WAXD). Finally, the crystal structure was investigated through wide angle X-ray diffraction (WAXD). 


\subsubsection{Transmission Electron Microscopy}

A JEOL, Inc. model 100S transmission electron microscope operating at $100 \mathrm{kV}$ was utilized to view the orientation of the nanotubes. Both drawn and undrawn samples were observed to determine the extent of orientation for the nanotubes. Ultrathin cross-sections of the fiber sample were microtomed and placed on standard TEM grids. The grids were placed in the microscope, brought into focus, viewed, and captured as digital images. The images were taken at magnifications of 25,000x and 50,000x.

\subsubsection{Scanning Electron Microscopy}

A JEOL, Inc. Field Emission model J600F scanning electron microscope, operating at $5 \mathrm{kV}$, was utilized to further examine the orientation of the nanotubes. Both drawn and undrawn samples were imaged to determine the effect of melt drawing on nanotube orientation. The samples were first cut with a sharp razor perpendicular to the fiber axis. Next, the samples were coated with an $\mathrm{Au} / \mathrm{Pd}$ film approximately $100 \AA$ thick to reduce charging. After coating, they were mounted with the microscope looking down the fiber axis, depicting the cross-section of the fiber perpendicular to the drawing direction. After mounting the samples, they were placed in the microscope, brought into focus, viewed, and captured as digital images. The images were taken at magnifications of 20,000x, 30,000x, and 40,000x.

\subsubsection{Wide Angle X-ray Diffraction}

A Bruker AXS wide angle X-ray diffractometer with a $\mathrm{Cu} \mathrm{K \alpha}$ average source $(\lambda=1.5418 \AA$ ) was utilized to look at the crystalline structure of the overall composite sample and to 
calculate the Herman orientation factor. The samples were run in both the transmission and reflection modes. In the reflection mode, the fibers were mounted on a $1 \mathrm{~cm} \mathrm{x} 1 \mathrm{~cm}$ silicon wafer. When mounting the sample in the unit, the fiber axis was oriented in the vertical direction. In this mode, the beam hit the sample at a predetermined angle, and the X-rays diffract into the detector creating the diffraction pattern. The instrument was set to run the scan with $2 \Theta$ set at $30^{\circ}$ and $\omega$ set at $15^{\circ}$. The scan was run for 900 seconds. From the diffraction pattern, the intensity is measured as a function of $2 \Theta$, and plots of intensity versus $2 \Theta$ are created. In the transmission mode, the fiber axis is oriented in the horizontal direction. The beam passes through the sample, and the X-rays diffract off of the sample to the detector creating cones seen as rings on the diffraction pattern. From these diffraction patterns, the intensity around each ring is measured and plot against $\chi$, the angle around the ring starting at 6 o'clock moving counter clockwise. Using ImageJ software, the transmission images were transformed to plots of intensity versus scattering vector, q. 


\section{RESULTS AND DISCUSSION}

\subsection{Thermal Analysis}

\subsubsection{Thermal Gravimetric Analysis}

Due to the high thermal stability of carbon nanotubes, the polypropylene matrix will degrade several hundred degrees before nanotubes in a nitrogen environment. Therefore, after the polypropylene completely degrades, the percent mass left in the pan is the concentration of nanotubes in the composite samples. These concentrations are compared with the initial concentrations to determine how much of the initial concentration is being lost in the mixing and extruding steps. From a preliminary test, the loss of nanotube concentration has been insignificant. Figure 4.1 shows an example TGA plot for a 3 wt $\%$ sample. As shown by the figure, the actual concentration of nanotubes in the sample is $2.4 \mathrm{wt} \%$. The reduction in mass of nanotubes can be attributed to two factors. When the PP and MWNT powders were mixed, the mass was not measured to a high level of precision. Additionally, the Minilab extruder contains area where the material can become trapped and not mix with the rest of the polymer. 


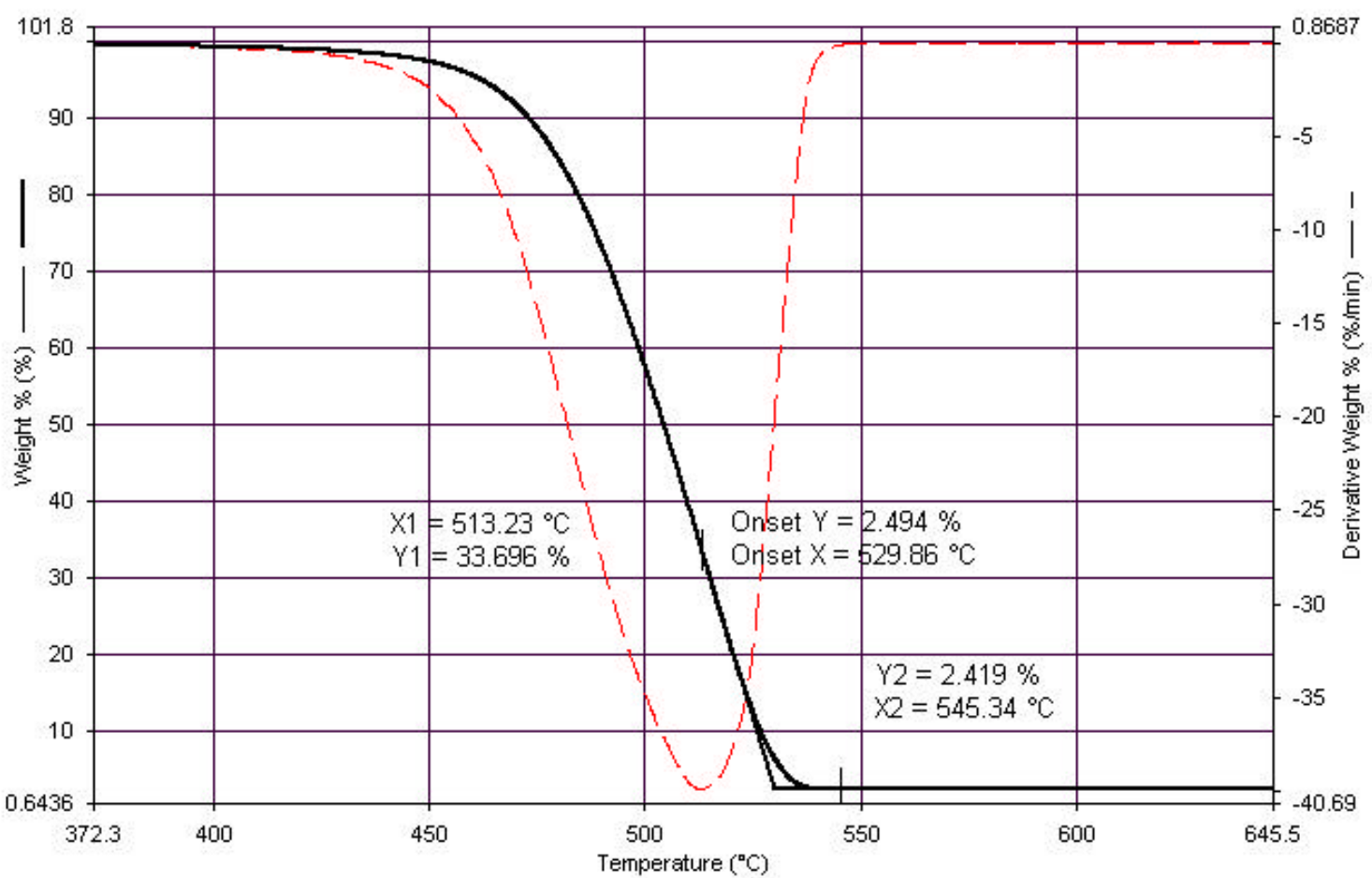

FIGURE 4.1. TGA plot of a PP/3 wt \% MWNT sample.

Further comparison of the $100 \%$ PP sample with the 3 wt \% MWNT sample, shows evidence of the thermal stability of carbon nanotubes. Figure 4.2 below shows a comparative plot of the $100 \%$ PP sample with the 3 wt \% MWNT sample. Due to the thermal stability of the nanotubes, the composite sample shows thermal stability (i.e. no mass loss) to $192^{\circ} \mathrm{C}\left(80^{\circ} \mathrm{C}\right.$ higher than that for pure PP). 


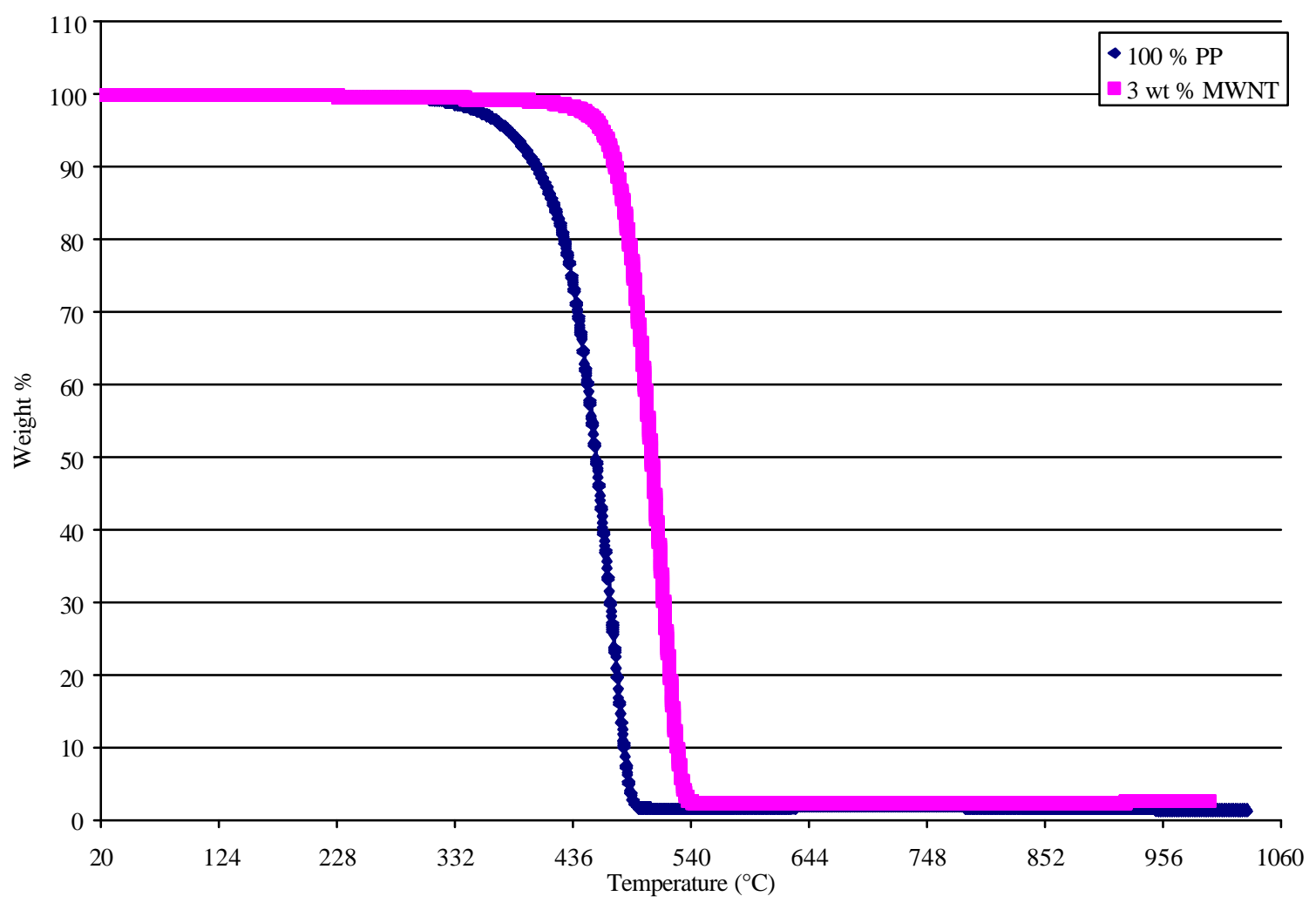

FIGURE 4.2. TGA Plot of $100 \%$ PP sample and 3 wt $\%$ MWNT sample.

\subsubsection{Differential Scanning Calorimetry}

Figure 4.3 shows the melting endotherms from differential scanning calorimetry (DSC) for 0 , 1 , and 3 wt $\%$ drawn (12:1) samples, respectively. The crystallinity was calculated using a $\Delta \mathrm{H}_{\mathrm{f}}{ }^{0}$ value of $207.1 \mathrm{~J} / \mathrm{gf}$ for $\mathrm{PP}^{62}$ and Equation 4.1, shown below. The percent crystallinity, onset temperature, and melting peak temperature are tabulated in Table 4.1.

$$
\% \text { Crystallinity }=\frac{\Delta H}{\Delta H_{f}^{o}} * 100
$$




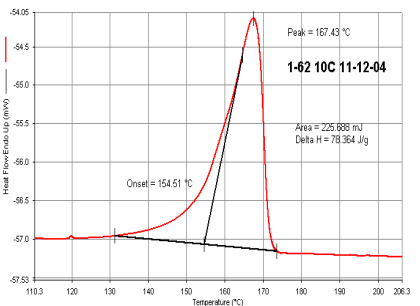

(a)

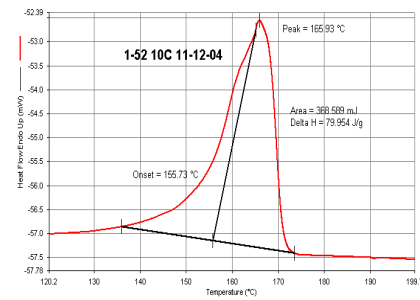

(b)

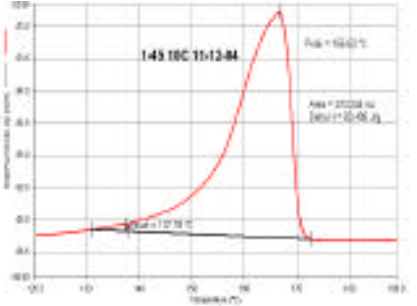

(c)

FIGURE 4.3. DSC Melting Peaks for (a) $0 \mathrm{wt} \%$, (b) $1 \mathrm{wt} \%$, and (c) 3 wt \% MWNTs in PP

TABLE 4.1. Percent Crystallinity, Onset Temperature, and Peak Melting Temperature

\begin{tabular}{|c|c|c|c|c|}
\hline $\begin{array}{c}\text { Figure } \\
4.2\end{array}$ & $\begin{array}{c}\text { wt \% } \\
\text { MWNT }\end{array}$ & Draw Ratio & $\begin{array}{c}\text { Crystallinty } \\
(\%)\end{array}$ & $\begin{array}{c}\text { Peak Melting T } \\
\left({ }^{\circ} \mathrm{C}\right)\end{array}$ \\
\hline (a) & 0 & $12: 1$ & 38 & 167 \\
\hline (b) & 1 & $12: 1$ & 39 & 166 \\
\hline (c) & 3 & $12: 1$ & 40 & 167 \\
\hline
\end{tabular}

Figure 4.3 shows the melting peak has a similar shape at the different loading levels. Table 4.1 shows little quantative change in the overall percent crystallinity, and peak melting temperature. The addition of up to $3 \mathrm{wt} \%$ MWNTs in PP did not significantly alter the overall crystallinity as observed by DSC.

\subsection{Mechanical Properties}

\subsubsection{Tensile}

Figure 4.4 shows a representative set of stress-strain curves for the 12:1 melt drawn samples at each nanotube concentration. The addition of nanotubes significantly alters the stressstrain behavior of the fibers. The ultimate stress, yield stress, and modulus increase with the addition of nanotubes. In contrast, the ultimate elongation slightly decreases with the 
addition of nanotubes. The significant increases in ultimate and yield stress combined with a small decrease in ultimate elongation leads to the observed increases in toughness.

Stress/Strain 12:1 Melt Drawn Fibers

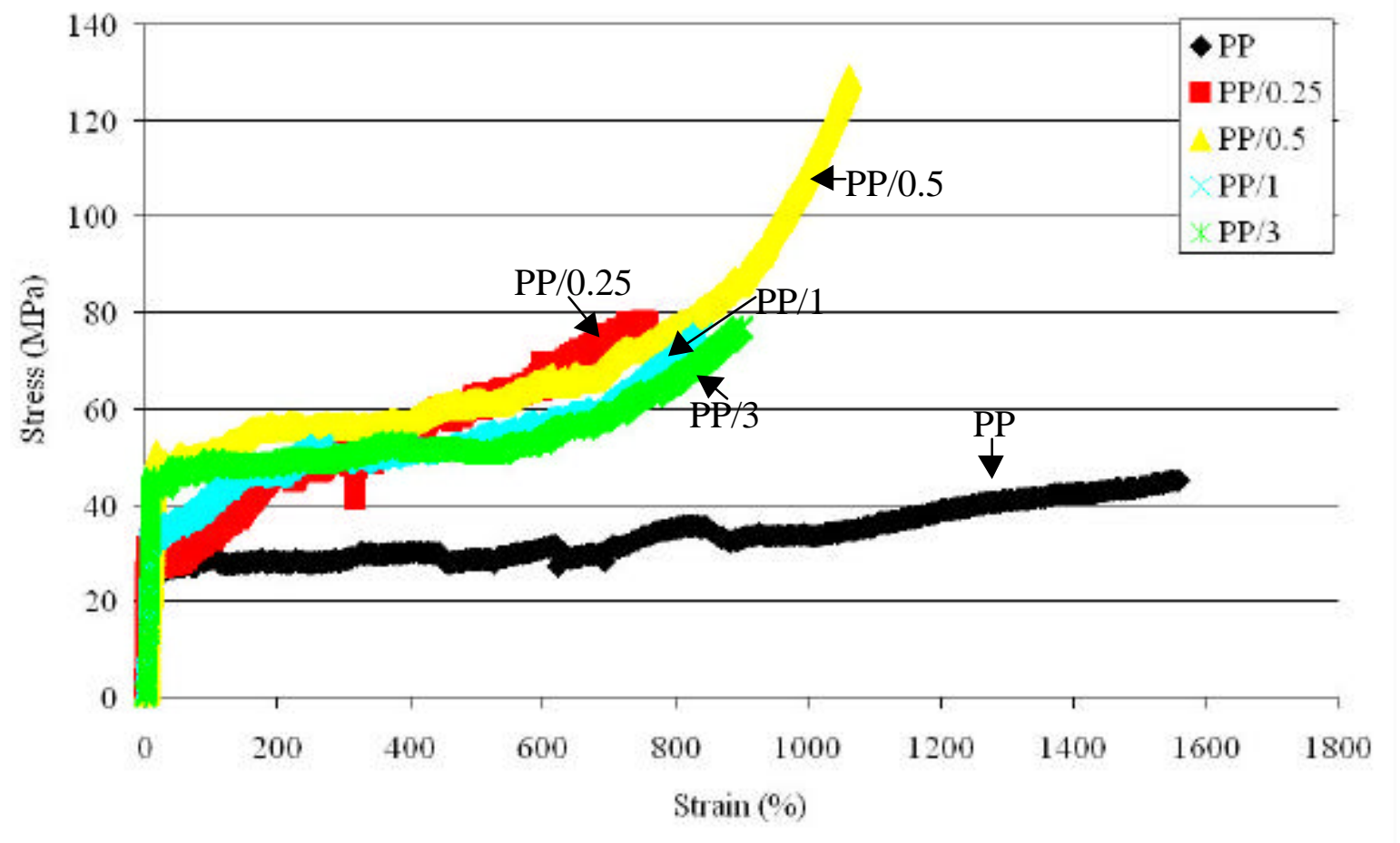

FIGURE 4.4. Stress-strain curves for $12: 1$ melt drawn fibers (diamond: PP, square: PP/0.25, triangle: PP/0.5, $\mathrm{x}: \mathrm{PP} / 1, *: \mathrm{PP} / 3)$.

Figure 4.5 shows the results for the tensile toughness (Fig. 4.5a), modulus (Fig. 4.5b), and yield stress (Fig. 4.5c) (see Section 3.2.3.1 for calculations) as a function of nanotube concentration (from 0 to $3 \mathrm{wt} \%$ ) and orientation (no draw, or unoriented, and oriented with a draw ratio of $12: 1,23: 1$, and 24:1). The white bars represent undrawn samples, the black bars represent fibers melt drawn to a 12:1 ratio, the vertical striped bars represent fibers coupled melt/solid drawn to a $23: 1$ ratio, and the horizontal striped bars represent fibers coupled melt/solid drawn to a 24:1 ratio. The error bars are based on the standard error of 
ten samples tested at each concentration level. Due to the difficulty of drawing the PP/3 wt\% MWNT samples to the $24: 1$ draw ratio, no data was collected for either the tensile toughness or modulus. In both the tensile toughness and modulus, optimal loading is achieved at 0.25 wt $\%$. 

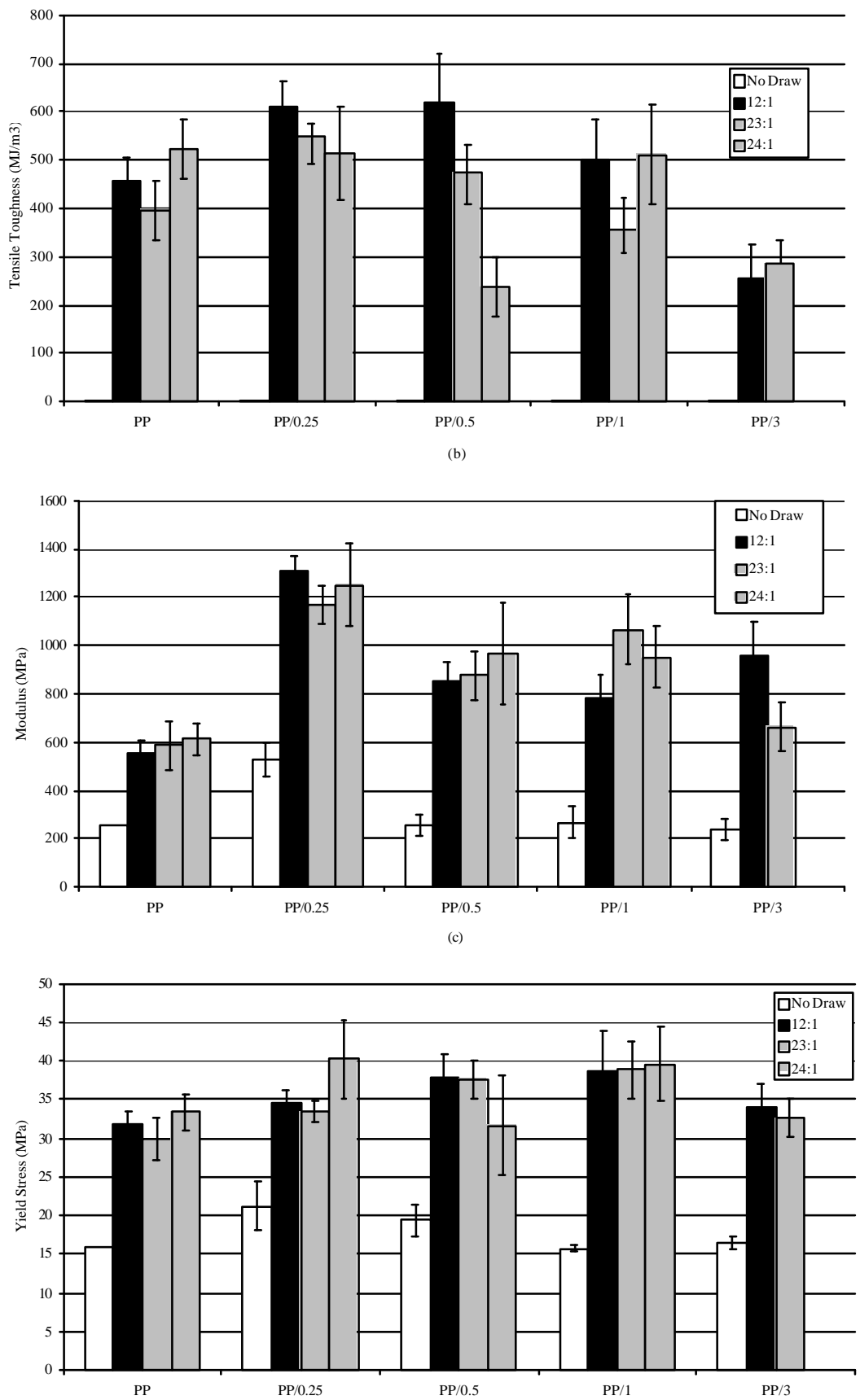

FIGURE 4.5. (a) Tensile Toughness (MJ/m3), (b) Modulus (MPa), and (c) Yield Stress (MPa) as a function of nanotube loading in PP for several draw ratios (white: no draw, black bar: 12:1 melt drawn, vertical stripe: 23:1 melt/solid drawn, horizontal stripe: $24: 1 \mathrm{melt} / \mathrm{solid}$ drawn) 
As observed in Figure 4.5a, the toughness of the unoriented (no draw) material is so low at all concentrations that it does not show up on the scale of the figure. Therefore, the orientation of PP alone improves tensile toughness. However, with the addition of nanotubes, the oriented samples show a statistically significant improvement at concentrations of $0.25-0.5$ wt \% MWNTs. As proposed by Gorga and Cohen, ${ }^{8}$ the toughness increase in amorphous materials results from the crack bridging ability of the nanotubes. As microcracks form, the nanotubes bridge the gap formed by the crack slowing down the crack propagation and increasing the overall material toughness. However, in semicrystalline materials, such as polypropylene, the nanotubes act as tie molecules between crystalline regions rather than bridging cracks. At concentrations greater than $0.5 \mathrm{wt} \%$, toughness decreases. The decrease results as the nanotubes begin to aggregate forming stress concentrations to similar those caused by voids in composite systems as shown by Wilbrink et al. $^{43}$

Similarly, Figure $4.5 \mathrm{~b}$ shows an increasing modulus with concentration up to $0.25 \mathrm{wt} \%$ followed by a decrease for both undrawn and drawn samples. Figure $4.5 \mathrm{~b}$ shows orientation of PP alone increases the modulus but not to the level attained with the addition of nanotubes. Adding low levels of nanotubes to PP improves the mechanical properties up to an optimal concentration ( 0.25 wt \%) above which nanotube aggregation leads to property decreases via stress concentrations (as discussed above). Although modulus decreases above $0.25 \mathrm{wt} \%$, the filled samples with orientation exhibit improved modulus over that of the drawn PP. The modulus increase can either be attributed to load transfer (from particle to 
matrix) or crystallinity changes in PP due to the addition of MWNTs. According to the rule of mixtures, the maximum modulus should reach $2.2 \mathrm{GPa}$ for a $0.25 \mathrm{wt} \%$ sample, assuming nanotube modulus of $1 \mathrm{TPa}$ and polypropylene modulus of $550 \mathrm{MPa}$. However, due to less than optimal load transfer, the maximum modulus achieved at a loading of $0.25 \mathrm{wt} \%$ is 1.3 GPa. As shown by electron microscopy (sections 4.3.1-4.3.2), the nanotubes are not perfectly aligned. Poor adhesion of the matrix material to the nanotubes could also limit the amount of load transfer. Finally, although the nanotubes have purity of greater than 95\%, some remnants of catalysts from the chemical vapor deposition process could still be present causing the nanotube to have a lower modulus than the calculated $1 \mathrm{TPa}$.

Likewise, Figure $4.5 \mathrm{c}$ shows statistically significant increases in the yield stress with the addition of nanotubes to the pure polypropylene. Furthermore, the increase to a maximum value followed by a decrease is also observed. However, the maximum occurs at a higher concentration range of about $0.5-1$ wt \% MWNTs. Additionally, the increase is not as significant and pronounced as in the case of the toughness and modulus. Therefore, the nanotubes are not as effective in increasing the stress at which plastic deformation occurs.

Additionally, little to no statistical difference between the melt drawn (12:1) samples and the coupled melt/solid drawn (23:1, 24:1) samples is observed (as shown by the error bars). However, the toughness for the $0.5 \mathrm{wt} \%$ sample is significantly lower due to an experimental anomaly. Therefore, the addition of coupled melt/solid drawn does not affect the values and trends achieved by melt drawing alone. The ability to melt draw to higher 
levels could possibly lead to further property improvements. Table 4.2 below gives a summary of the average mechanical properties for each loading level and draw ratio.

TABLE 4.2. Summary of mechanical properties for PP and composite samples as a function of nanotube concentration and fiber draw ratio.

\begin{tabular}{|c|c|c|c|c|c|}
\hline $\begin{array}{c}\text { Sample } \\
\text { Name }\end{array}$ & $\begin{array}{c}\text { wt \% } \\
\text { MWNT }\end{array}$ & $\begin{array}{c}\text { Draw } \\
\text { Ratio }\end{array}$ & $\begin{array}{c}\text { Tensile } \\
\text { Toughness } \\
\left(\mathrm{MJ} / \mathrm{m}^{3}\right)\end{array}$ & $\begin{array}{c}\text { Modulus } \\
(\mathrm{MPa})\end{array}$ & $\begin{array}{c}\text { Yield } \\
\text { Stress } \\
(\mathrm{MPa})\end{array}$ \\
\hline $\mathrm{PP}$ & 0 & 0 & 0.8376 & 257.32 & 15.811 \\
\hline $\mathrm{PP}$ & 0 & $12: 1$ & 457.362 & 551.367 & 31.822 \\
\hline $\mathrm{PP}$ & 0 & $23: 1$ & 396.667 & 584.723 & 29.867 \\
\hline $\mathrm{PP}$ & 0 & $24: 1$ & 523 & 611.425 & 33.343 \\
\hline $\mathrm{PP} / 0.25$ & 0.25 & 0 & 1.1032 & 528.251 & 21.242 \\
\hline $\mathrm{PP} / 0.25$ & 0.25 & $12: 1$ & 608 & 1312.312 & 34.553 \\
\hline $\mathrm{PP} / 0.25$ & 0.25 & $23: 1$ & 549 & 1166.531 & 33.446 \\
\hline $\mathrm{PP} / 0.25$ & 0.25 & $24: 1$ & 512 & 1250.094 & 40.269 \\
\hline $\mathrm{PP} / 0.5$ & 0.5 & 0 & 1.707 & 253.8 & 19.371 \\
\hline $\mathrm{PP} / 0.5$ & 0.5 & $12: 1$ & 620 & 852.403 & 37.961 \\
\hline $\mathrm{PP} / 0.5$ & 0.5 & $23: 1$ & 474 & 876.563 & 37.687 \\
\hline $\mathrm{PP} / 0.5$ & 0.5 & $24: 1$ & 236.667 & 966.781 & 31.672 \\
\hline $\mathrm{PP} / 1$ & 1 & 0 & 0.6564 & 266.2 & 15.784 \\
\hline $\mathrm{PP} / 1$ & 1 & $12: 1$ & 500 & 782.303 & 38.806 \\
\hline $\mathrm{PP} / 1$ & 1 & $23: 1$ & 355 & 1064.408 & 38.831 \\
\hline $\mathrm{PP} / 1$ & 1 & $24: 1$ & 511 & 949.423 & 39.951 \\
\hline $\mathrm{PP} / 3$ & 3 & 0 & 0.8569 & 237.61 & 16.425 \\
\hline $\mathrm{PP} / 3$ & 3 & $12: 1$ & 254 & 957.373 & 34.171 \\
\hline $\mathrm{PP} / 3$ & 3 & $23: 1$ & 285.556 & 662.416 & 32.568 \\
\hline & & & & & \\
\hline
\end{tabular}

\subsubsection{Dynamic Mechanical Analysis}

In viscoelastic materials, such as polymers, the process involved with molecular relaxation or rearrangement occur at accelerated rates at high temperatures, and time and temperature exhibit a direct equivalency. Due to these factors, the response of a material to an environment for long periods of time can be observed utilizing time-temperature experiments in a reasonable experimental time frame. The experiments are performed at several 
temperature intervals and shifted to a reference temperature. Figure 4.6 shows the storage modulus as a function of frequency for seven temperatures (ranging from $30-150^{\circ} \mathrm{C}$ ) for the 0.25 wt \% MWNT sample. At each temperature the frequency ranged from 0.01 to $100 \mathrm{~Hz}$.

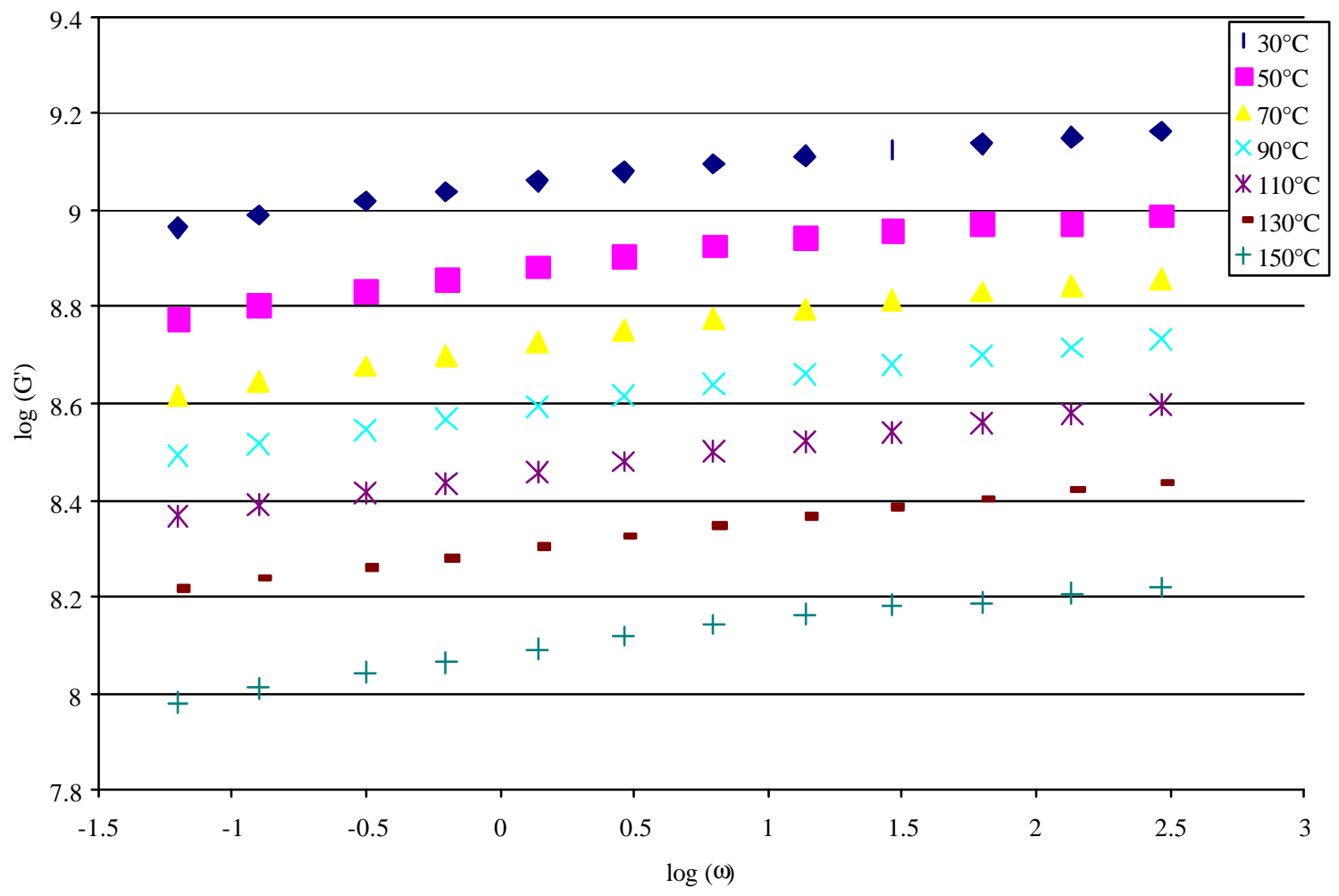

FIGURE 4.6. Storage modulus, $\mathrm{G}$ ', in $\mathrm{Pa}$ as a function of frequency, $\omega$, in $\mathrm{rad} / \mathrm{s}$ and temperature (diamond: $30^{\circ} \mathrm{C}$, square: $50^{\circ} \mathrm{C}$, triangle: $70^{\circ} \mathrm{C}, \mathrm{x}: 90^{\circ} \mathrm{C}, *: 110^{\circ} \mathrm{C},-: 130^{\circ} \mathrm{C},+: 150^{\circ} \mathrm{C}$ ) for 0.25 wt $\%$ MWNTs in PP (12:1 draw ratio)

Horizontally shifting the curves around a reference temperature, i.e. $90^{\circ} \mathrm{C}$, produced the master curve. Figure 4.6 shows the master curve for the $0.25 \mathrm{wt} \%$ sample. This master curve does not show the full S-shape due to the experimental range only covering part of the viable temperature range for the material. Therefore, the material response can only be analyzed within the resulting rubbery region. 


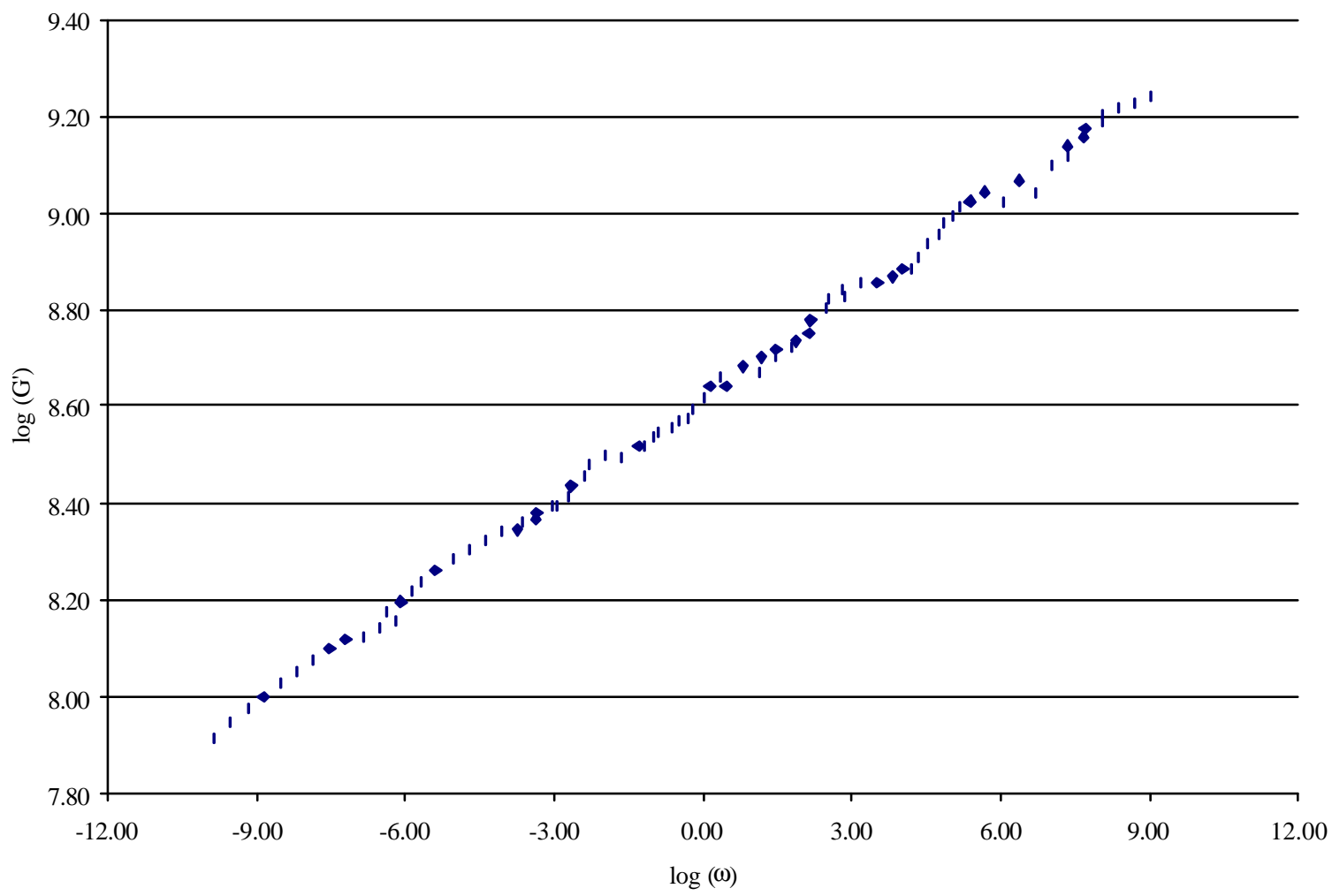

FIGURE 4.7. Master curve for the 0.25 wt $\%$ MWNT sample melt drawn fiber (12:1 draw ratio). 


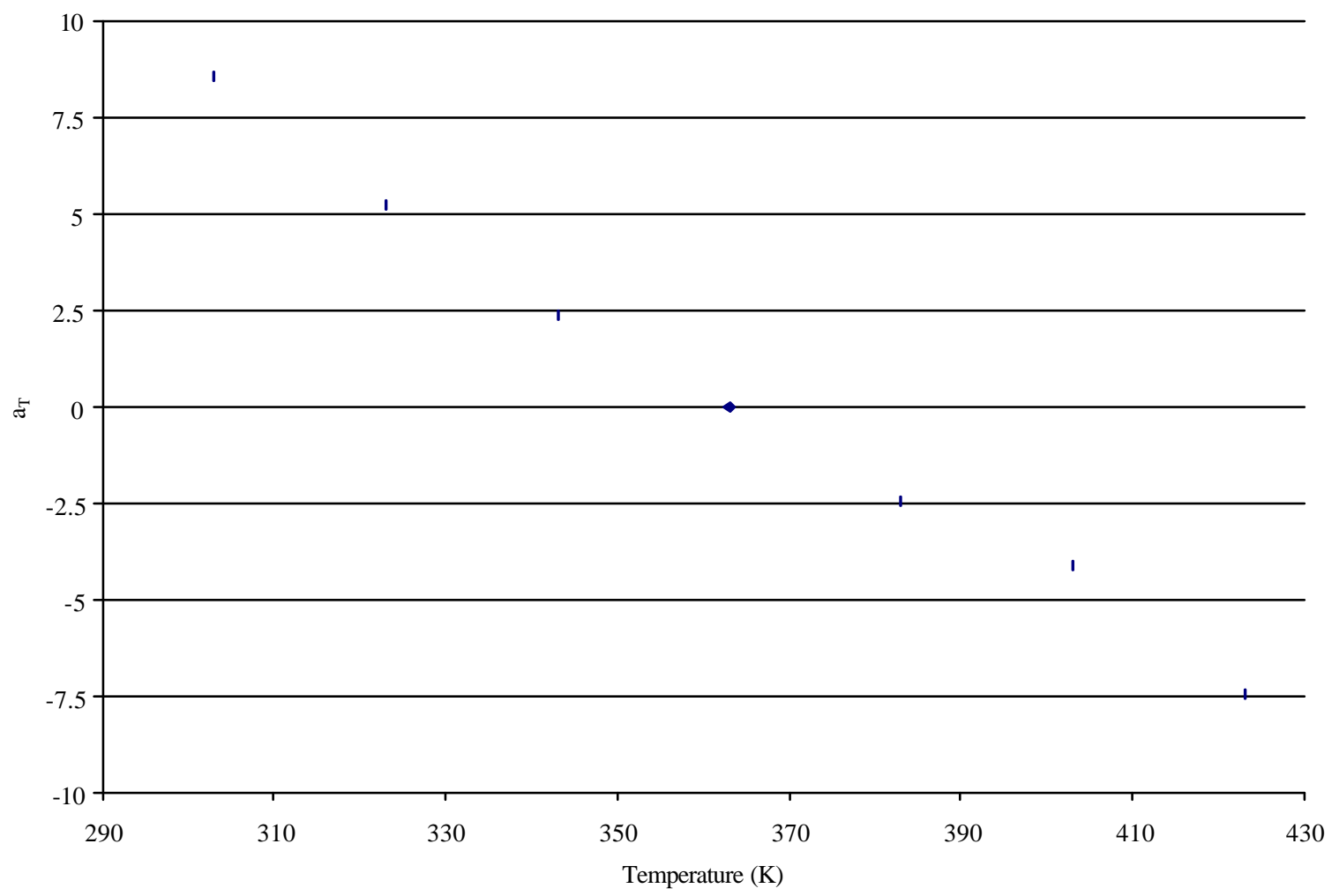

FIGURE 4.8. Shift factor as a function of temperature for $0.25 \mathrm{wt} \%$ MWNTs in PP (12:1 draw ratio) with Arrhenius model.

The $\mathrm{x}$-axis shift factor, $\mathrm{a}_{\mathrm{T}}$, for each temperature is plotted as a function of the temperature. The data can be fit using the Arrhenius equation (Equation 4.2) as a mathematical model (as shown in Figure 4.8).

$$
\ln a_{T}=\frac{-E_{a}}{R}\left(\frac{1}{T_{o}}-\frac{1}{T}\right)
$$

In Equation 4.2, $\mathrm{E}_{\mathrm{a}}$ is the activation energy of the polymer system, $\mathrm{a}_{\mathrm{T}}$ is the time-based shift factor, $\mathrm{R}$ is the gas constant, $\mathrm{T}$ is the measurement temperature, and $\mathrm{T}_{0}$ is the reference temperature. As the polymer is strained, it must overcome an energy barrier to allow the chains to move and rotate about the main chain bonds. The energy barrier is known as the 
activation energy of the polymer system. ${ }^{70}$ Figure 4.9 below gives of plot of this activation energy as a function of nanotube loading with errors bars representing the standard error of the Arrhenius model fit for the $0.25 \mathrm{wt} \%$ sample at the $12: 1$ draw ratio.

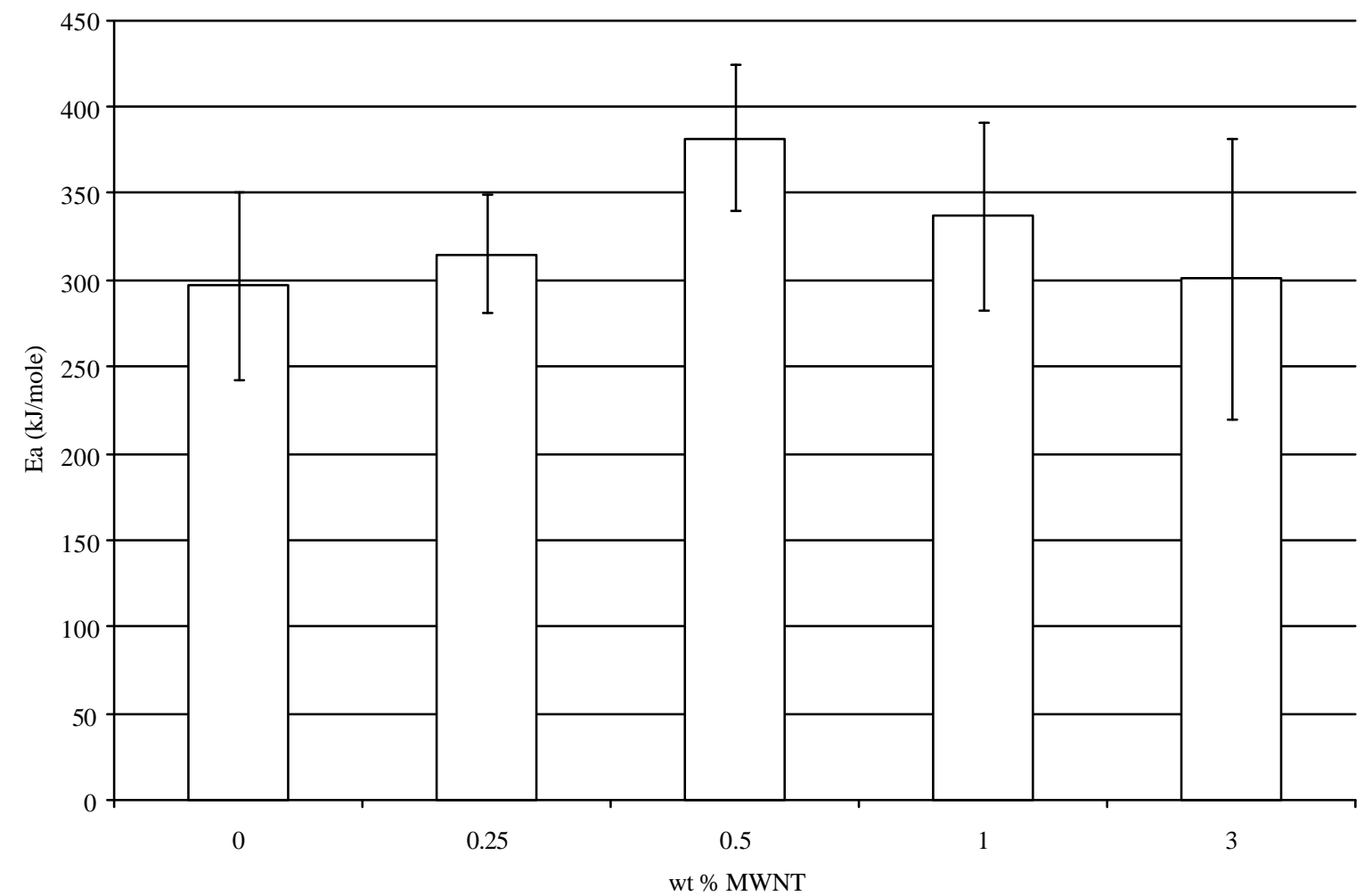

FIGURE 4.9. Activation energy of fibers with $12: 1$ draw ratio.

Similar to the conventional tensile data, a trend to a maximum with the addition of nanotubes is seen in the activation energy data. However, the trend is not statistical significant as shown by the error bars. With the addition of high modulus nanotubes, the resistance to strain would increase similar to the toughness (resistance to rupture) and modulus (resistance to deformation). However, as the concentration of nanotubes increases to concentrations greater than $0.5 \mathrm{wt} \%$, agglomeration of the nanotubes occurs. The agglomeration leads to 
stress concentrations and therefore less resistance to strain. In a similar manner, the load transfer ability and ability to act as tie molecules of the nanotubes decrease as nanotube agglomeration occurs.

\subsection{Morphology}

\subsubsection{Transmission Electron Microscopy}

Figure 4.11 shows transmission electron microscopy images of a 3 wt \% MWNTs in PP both unoriented (no draw) and oriented at 12:1 draw ratio. These images depict the cross-section of the fiber normal to the drawing direction (see Figure 4.10). Comparing the two images reveals how melt drawing the nanocomposite orients the nanotubes. In the unoriented image (Fig. 4.11a) whole nanotubes lying at various oblique angles are observed; whereas, the image of the drawn sample (Fig. 4.11b) shows primarily the tips of the nanotubes (which run parallel to the fiber axis), therefore indicating flow induced orientation along the fiber axis.

FIGURE 4.10. Schematic of fiber orientation for electron microscopy images. 


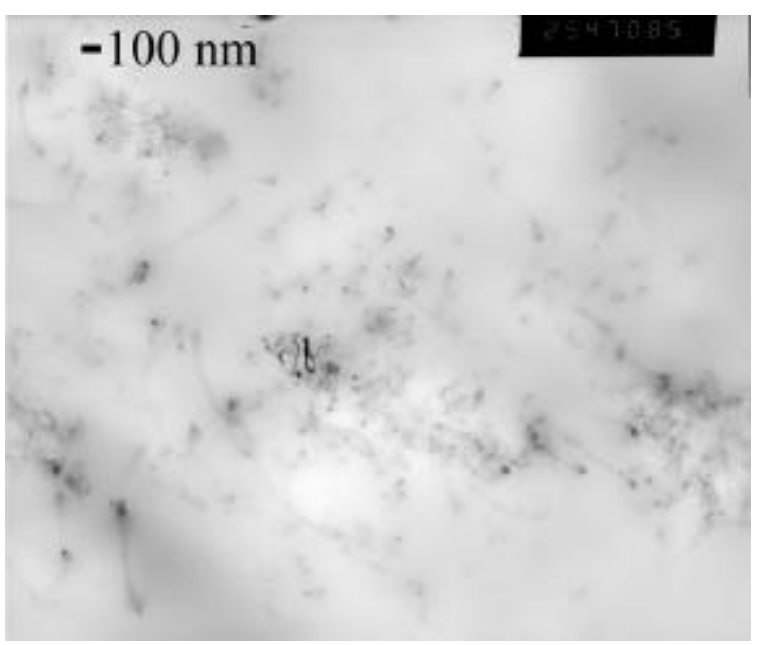

(a)

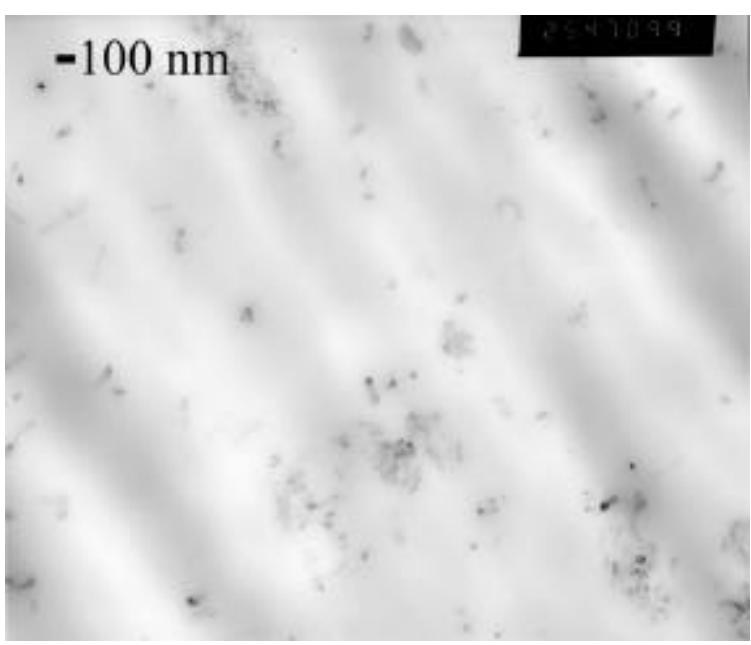

(b)

FIGURE 4.11. TEM Images of 3 wt \% MWNT in PP ((a) unoriented, (b) oriented, 12:1 draw ratio).

\subsubsection{Scanning Electron Microscopy}

Figure 4.12 shows scanning electron microscopy images of a 3 wt $\%$ MWNTs in PP both unoriented (no draw) and oriented at 12:1 draw ratio. These images depict the cross-section of the fiber normal to the drawing direction (see Figure 4.10). Comparing the two SEM images further reveals how drawing the nanocomposite orients the nanotubes. In the unoriented image (Fig. 4.12a) whole nanotubes lying at various oblique angles are observed; whereas, the image of the drawn sample (Fig. 4.12b) shows only the tips of the nanotubes (which run parallel to the fiber axis), therefore indicating flow induced orientation along the fiber axis. 


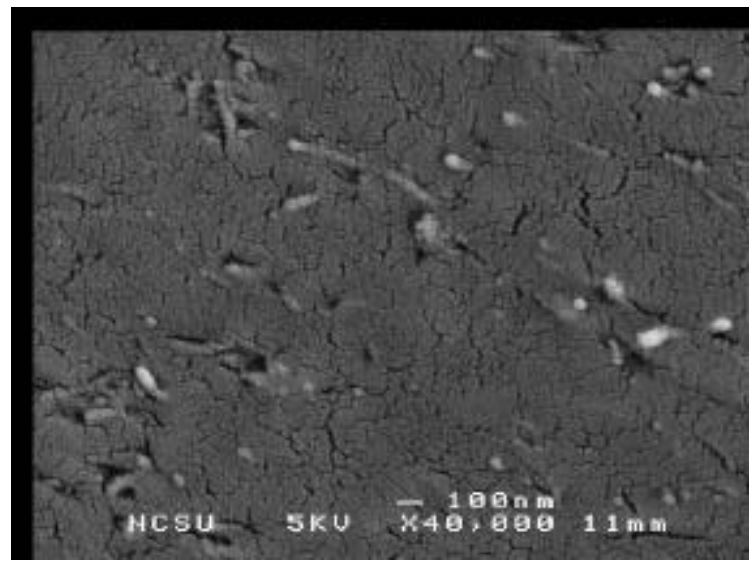

(a)

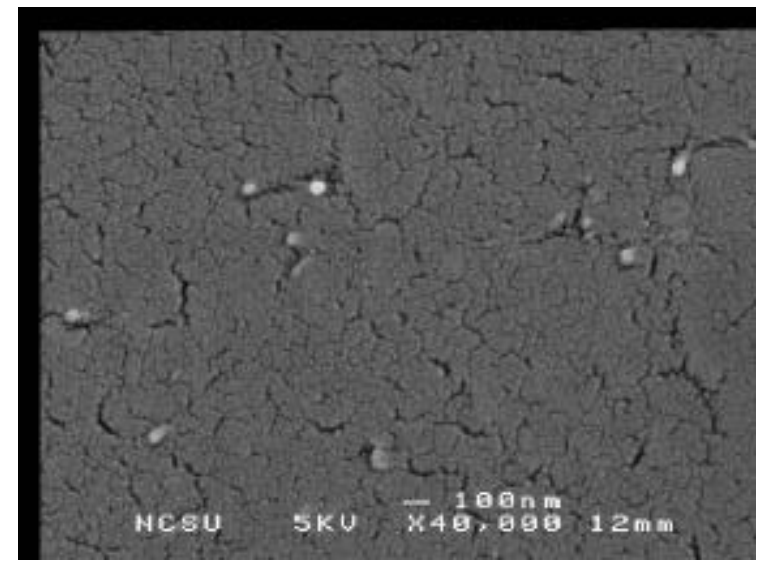

(b)

FIGURE 4.12. SEM Images of 3 wt \% MWNT in PP ((a) unoriented, (b) oriented, 12:1 draw ratio).

Qualitative evidence of nanotube alignment is observed in both the transmission and scanning electron microscopy images. Therefore as the material is being extruded and melt drawn, the extensional flow causes nanotube orientation along the fiber axis. As a result, the maximum load transfer can be achieved leading to the property improvements discussed in sections 4.2.1 and 4.2.2.

\subsubsection{Wide Angle X-ray Diffraction}

Figure 4.13 gives the 2D Wide Angle X-ray Diffraction patterns and corresponding scattering vector versus intensity plots for drawn samples (12:1) at 0 and 3 wt $\%$ loading. 

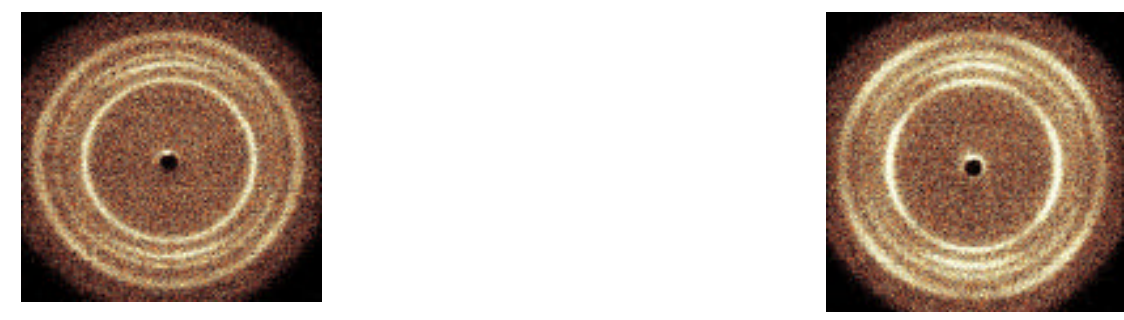

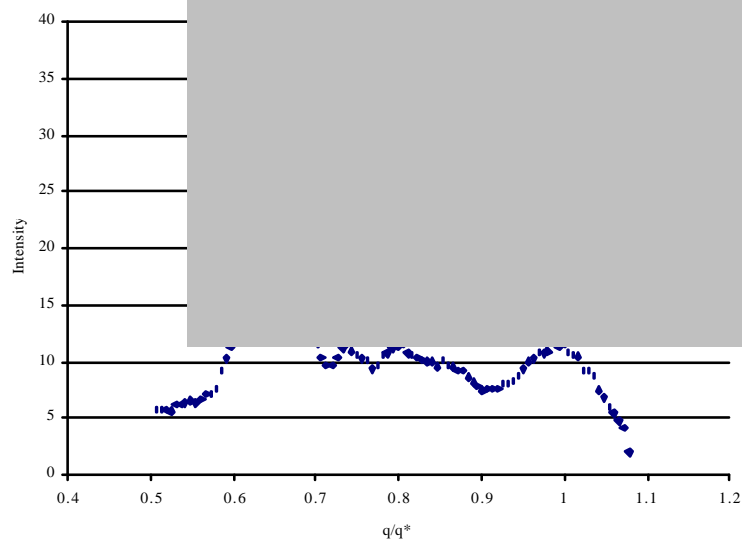

(a)

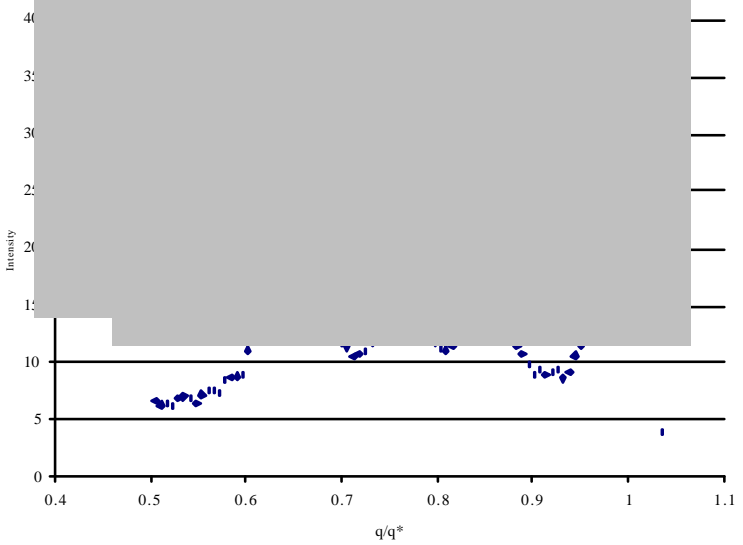

(b)

FIGURE 4.13. WAXD Patterns for (a) $0 \mathrm{wt} \%$ and (b) $3 \mathrm{wt} \%$ MWNTs in PP with 12:1 draw ratio.

The plots both reveal the four peaks corresponding to the four ring pattern common to PP fiber X-ray diffraction. However, all four peaks for the 3 wt $\%$ sample (Figure 4.13b) are more distinct and intense than the peaks for the 0 wt $\%$ sample (Figure 4.13a). Similar transitions from in intensity were observed by Broda ${ }^{63}$ in pure PP fiber extruded with increasing take-up speeds. The study concluded the decrease in intensity resulted from the presence of mesophase and $\alpha$ phase PP crystallinity. Based on comparison with Broda's Xray diffraction plots, the $0 \mathrm{wt} \%$ sample contains mesophase and $\alpha$ phase PP crystallinity. However, the 3 wt \% sample contains only $\alpha$ phase PP crystallinity. The different PP crystal phases can be responsible for changes in the mechanical properties. ${ }^{62}$ 
Using the intensity as a function of angle, $\chi$, around each diffraction ring, the Herman's orientation factor can be determined. The Herman's orientation factor $\left(\mathrm{P}_{2}\right)$ is defined in Equation 4.3:

$$
P_{2}=\frac{3<\cos ^{2} \chi>-1}{2}
$$

In Equation 4.3, $\left\langle\cos ^{2} \chi\right\rangle$ is the average cosine squared value for the diffraction ring and is calculated using the following equation:

$$
<\cos ^{2} \chi>=\frac{\sum_{i=0}^{90} I_{i} \cos ^{2} \chi_{i} \sin \chi_{i}}{\sum_{i=0}^{90} I_{i} \sin \chi_{i}}
$$

In Equation 4.4, $\mathrm{I}$ and $\chi$ are the intensity and angle at the $\mathrm{i}^{\text {th }}\left(0.5^{\circ}\right.$ step) position along the diffraction ring. The diffraction data was corrected to shift the background intensity to a value of zero. After correcting the background, the Herman's orientation factors for each crystallographic ring of a virgin polypropylene sample and a $3 \mathrm{wt} \%$ multi-wall nanotube loaded sample were calculated using equations 4.3 and 4.4. The results are tabulated in Table 4.3.

TABLE 4.3. Herman's Orientation Factors.

\begin{tabular}{|c|c|c|c|c|}
\hline Sample & 110 & 040 & 130 & 131 \\
\hline $0 \%$ Unoriented & 0.42 & -.22 & -.08 & -.18 \\
\hline $0 \%$ Oriented & 0.76 & -.37 & -.33 & -.24 \\
\hline $3 \%$ Unoriented & -.10 & -.08 & -.11 & -.27 \\
\hline $3 \%$ Oriented & .43 & -.34 & -.26 & -.22 \\
\hline
\end{tabular}

The Herman's orientation factor can vary between -0.5 to 1 . If the factor is -0.5 , the crystal plane is oriented perpendicular to the reference direction of $\chi=0$, the direction of draw, 
whereas a factor of 1 denotes orientation parallel to the reference direction. Random orientation is observed when the factor equals 0 . The Herman's orientation analysis can be used to quantify crystal orientation as a function of nanotube concentration and orientation (of both NTs and polymer molecules). In the as-extruded (or undrawn) samples, the nanotube addition promotes isotropization of the composite as demonstrated by the $\mathrm{P}_{2}$ coefficients being slightly negative but close to zero (for nanotube filled samples). Further examination of the change in the $\mathrm{P}_{2}$ coefficients $\left(\Delta \mathrm{P}_{2}=\mathrm{P}_{2}\right.$,oreinted $-\mathrm{P}_{2}$, unoriented $)$ from the unoriented to the oriented state demonstrates the effects of drawing both pure PP and filled PP ( with 3 wt \% MWNT). The $\Delta \mathrm{P}_{2}$ factors are tabulated in Table 4.4. As shown by Table 4.4, drawing the fiber samples results in improved orientation overall. The 110 crystal planes become more oriented along the fiber axis, whereas the 040 and 130 planes become more oriented perpendicular to the fiber axis. However, the $13 \hat{i}$ planes remains randomly oriented. It is germane to note that the orientation along the fiber axis for the 110 plane is more highly oriented for the nanotube loaded sample. Likewise, the orientation perpendicular to the fiber direction for the 040 plane is more highly oriented in the nanotube loaded sample. Whereas, the opposite is true of the 130 plane.

TABLE 4.4. $\Delta \mathrm{P}_{2}$ Values

\begin{tabular}{|c|c|c|}
\hline Ring & $0 \mathrm{wt} \% \mathrm{MWNT}$ & 3 wt \% MWNT \\
\hline 110 & .34 & .53 \\
\hline 040 & -.15 & -.26 \\
\hline 130 & -.25 & -.15 \\
\hline 131 & -.06 & .05 \\
\hline
\end{tabular}




\section{CONCLUSIONS}

Dispersion and orientation of multi-wall carbon nanotubes (MWNT) in polypropylene (PP) simultaneously created a tougher and stiffer material. The tensile properties increased as a function of loading to a maximum value at a loading level of $0.25 \mathrm{wt} \%$ MWNTs. Toughness increases up to $32 \%$ over pure PP were due to the nanotubes acting as tie molecules between the crystalline regions. Modulus increases of up to $138 \%$ were due to load transfer and crystalline structure changes. Differential scanning calorimetry supported the conclusion of modulus increases via load transfer rather than an increase in crystallinity. However, wide angle X-ray diffraction indicates a crystal structure change from $\alpha$ phase and mesophase to only $\alpha$ phase with nanotube loading in oriented samples. The activation energy, calculated from dynamic mechanical experiments, also revealed an increasing trend to a maximum as a function of nanotube loading; however, it was on the cusp of statistical significance. In conclusion, the mechanical properties (modulus, toughness, and activation energy) all exhibited maximum value at a low nanotube loading ( $<1 \mathrm{wt} \%$ MWNTs).

In drawn samples, the nanotubes were shown by transmission electron microscopy and scanning electron microscopy to be highly aligned. Although nanotube orientation was revealed through these techniques, isotropization (for randomly dispersed nanotubes) and increased orientation for the melt drawn (or oriented) samples was quantified by Herman's orientation factor analysis of the wide angle X-ray diffraction patterns. 
Melt mixing 0.25 wt $\%$ MWNTs in PP followed by melt drawing at a 12:1 ratio produced a composite fiber with excellent nanotube dispersion and alignment. The fiber was tougher, stiffer, and more resistant to oscillating strain than the drawn pure PP fiber. Furthermore, the crystal structure changed from $\alpha$ and mesophase in the pure PP fiber to only $\alpha$ phase in the composite fiber. However, changes were not observed in the overall crystallinity and crystal orientation. Through this work, the processing and properties of a promising material were developed with the possibility for use in advanced fiber applications. 


\section{FUTURE WORK}

Many possibilities for future work for this project still remain and could lead to the creation of innovative materials with unique properties. In addition to the mechanical and morphological properties, the conductivities of the composite samples should be tested. Research shows gains in electrical conductivity of other similar polymer/nanotube composites. However, little research exists on the thermal behavior of such composite systems. Measurements of the conductivity should be first preformed at the levels with the optimal mechanical properties. However, optimization of the mechanical, morphological, and conductive properties could lead to application specific materials. Models could be developed to determine the optimal nanotube orientation and concentration to achieve a set of properties for each individual application. Research such as this could lead to the next new generation of materials.

In addition to further optimization with the current materials, investigations of different nanotubes should be performed. With the development of new nanotube production methods, new possibilities are created. For example, some of the newer technologies allow for more control of the nanotube length and diameter. Multi-wall nanotubes with smaller diameters have been suggested to exhibit properties closer to those of single-wall nanotubes, such as better mechanical properties. Additionally, the smaller multi-wall nanotubes still exhibit lower tendency to agglomerate than single-wall nanotubes. With these results, stronger and tougher polymer nanotube composites could be created. Furthermore, the effects of nanotube length provide another area of possible study. Combining this research 
with the current research could lead to polymer/nanotube composites with exceptionally high strength, toughness, and conductivity.

In addition, experiments could be performed to investigate the possibility of controlling the nanotube orientation. Composite samples with varying nanotube orientation could be created using methods, such as magnetic fields. The permeability of the material could be tested with the different nanotube orientations. With the results from these experiments, models could be developed to produce samples with different permeability values. Using the models, application specific materials could be manufactured for membranes or even impermeable biohazard suits.

After optimizing the nanotube concentration, orientation, and geometry, a large scale production method could be developed. These methods would utilize current production techniques to produce the materials on an industrial scale. Processing parameters sets could be developed to further utilize the materials in various applications from space to everyday items. Using the parameters, materials could be easily manufactured for specific applications. For example, a highly electrically conductive material could be manufactured with increased strength or thermal conductivity. Such parameter sets would include nanotube concentration, nanotube orientation, nanotube geometry, matrix material, screw speed, extrusion temperature, residence time, and winding speed, which could be modified to get the desired properties. From these sets, companies utilize current manufacturing processes to begin the manufacture of the next generation of high performance materials. 


\section{REFERENCES}

1. $\quad$ Iijima, S. Nature 1991, 354, (6348), 56-58.

2. Ebbesen, T. W.; Lezec, H. J.; Hiura, H.; Bennett, J. W.; Ghaemi, H. F.; Thio, T. Nature 1996, 382, (6586), 54-56.

3. Hone, J.; Whitney, M.; Piskoti, C.; Zettl, A. Physical Review B 1999, 59, (4), R2514R2516.

4. Treacy, M. M. J.; Ebbesen, T. W.; Gibson, J. M. Nature 1996, 381, (6584), 678-680.

5. Bin, Y. Z.; Kitanaka, M.; Zhu, D.; Matsuo, M. Macromolecules 2003, 36, (16), 62136219.

6. Jang, J.; Bae, J.; Yoon, S. H. Journal Of Materials Chemistry 2003, 13, (4), 676-681.

7. $\quad$ Potschke, P.; Fornes, T. D.; Paul, D. R. Polymer 2002, 43, (11), 3247-3255.

8. Gorga, R. E.; Cohen, R. E. Journal Of Polymer Science Part B-Polymer Physics 2004, 42, (14), 2690-2702.

9. Iijima, S.; Ichihashi, T. Nature 1993, 363, (6430), 603-605.

10. Lau, K. T.; Hui, D. Composites Part B-Engineering 2002, 33, (4), 263-277.

11. Lordi, V.; Yao, N. Journal Of Materials Research 2000, 15, (12), 2770-2779.

12. Harris, P. J. F. International Materials Reviews 2004, 49, (1), 31-43.

13. Qin, L. C.; Iijima, S. Chemical Physics Letters 1997, 269, (1-2), 65-71.

14. Thostenson, E. T.; Ren, Z. F.; Chou, T. W. Composites Science And Technology 2001, 61, (13), 1899-1912.

15. Schlittler, R. R.; Seo, J. W.; Gimzewski, J. K.; Durkan, C.; Saifullah, M. S. M.; Welland, M. E. Science 2001, 292, (5519), 1136-1139.

16. Lu, J. P. Journal Of Physics And Chemistry Of Solids 1997, 58, (11), 1649-1652.

17. Robertson, D. H.; Brenner, D. W.; Mintmire, J. W. Physical Review B 1992, 45, (21), 12592-12595.

18. Yakobson, B. I.; Brabec, C. J.; Bernholc, J. Physical Review Letters 1996, 76, (14), 2511-2514.

19. Lourie, O.; Wagner, H. D. Journal Of Materials Research 1998, 13, (9), 2418-2422.

20. Krishnan, A.; Dujardin, E.; Ebbesen, T. W.; Yianilos, P. N.; Treacy, M. M. J.

Physical Review B 1998, 58, (20), 14013-14019.

21. Salvetat, J. P.; Briggs, G. A. D.; Bonard, J. M.; Bacsa, R. R.; Kulik, A. J.; Stockli, T.; Burnham, N. A.; Forro, L. Physical Review Letters 1999, 82, (5), 944-947.

22. Walters, D. A.; Ericson, L. M.; Casavant, M. J.; Liu, J.; Colbert, D. T.; Smith, K. A.; Smalley, R. E. Applied Physics Letters 1999, 74, (25), 3803-3805.

23. Li, F.; Cheng, H. M.; Bai, S.; Su, G.; Dresselhaus, M. S. Applied Physics Letters 2000, 77, (20), 3161-3163.

24. Pan, Z. W.; Xie, S. S.; Lu, L.; Chang, B. H.; Sun, L. F.; Zhou, W. Y.; Wang, G.; Zhang, D. L. Applied Physics Letters 1999, 74, (21), 3152-3154.

25. Berber, S.; Kwon, Y. K.; Tomanek, D. Physical Review Letters 2000, 84, (20), 46134616.

26. Benedict, L. X.; Crespi, V. H.; Louie, S. G.; Cohen, M. L. Physical Review B 1995, 52, (20), 14935-14940. 
27. Li, H. J.; Guan, L. H.; Shi, Z. J.; Gu, Z. N. Journal Of Physical Chemistry B 2004, 108, (15), 4573-4575.

28. Li, Y. L.; Kinloch, I. A.; Windle, A. H. Science 2004, 304, (5668), 276-278.

29. Zhang, M.; Atkinson, K. R.; Baughman, R. H. Science 2004, 306, (5700), 1358-1361.

30. Ericson, L. M.; Fan, H.; Peng, H. Q.; Davis, V. A.; Zhou, W.; Sulpizio, J.; Wang, Y. H.; Booker, R.; Vavro, J.; Guthy, C.; Parra-Vasquez, A. N. G.; Kim, M. J.; Ramesh, S.; Saini, R. K.; Kittrell, C.; Lavin, G.; Schmidt, H.; Adams, W. W.; Billups, W. E.; Pasquali, M.; Hwang, W. F.; Hauge, R. H.; Fischer, J. E.; Smalley, R. E. Science 2004, 305, (5689), 1447-1450.

31. Zhou, W.; Vavro, J.; Guthy, C.; Winey, K. I.; Fischer, J. E.; Ericson, L. M.; Ramesh, S.; Saini, R.; Davis, V. A.; Kittrell, C.; Pasquali, M.; Hauge, R. H.; Smalley, R. E. Journal Of Applied Physics 2004, 95, (2), 649-655.

32. Sennett, M.; Welsh, E.; Wright, J. B.; Li, W. Z.; Wen, J. G.; Ren, Z. F. Applied Physics A-Materials Science \& Processing 2003, 76, (1), 111-113.

33. Haggenmueller, R.; Gommans, H. H.; Rinzler, A. G.; Fischer, J. E.; Winey, K. I. Chemical Physics Letters 2000, 330, (3-4), 219-225.

34. Andrews, R.; Weisenberger, M. C. Current Opinion In Solid State \& Materials Science 2004, 8, (1), 31-37.

35. Bubert, H.; Haiber, S.; Brandl, W.; Marginean, G.; Heintze, M.; Bruser, V. Diamond And Related Materials 2003, 12, (3-7), 811-815.

36. Eitan, A.; Jiang, K. Y.; Dukes, D.; Andrews, R.; Schadler, L. S. Chemistry Of Materials 2003, 15, (16), 3198-3201.

37. Shaffer, M. S. P.; Fan, X.; Windle, A. H. Carbon 1998, 36, (11), 1603-1612.

38. Bhattacharyya, A. R.; Sreekumar, T. V.; Liu, T.; Kumar, S.; Ericson, L. M.; Hauge, R. H.; Smalley, R. E. Polymer 2003, 44, (8), 2373-2377.

39. Jin, Z.; Pramoda, K. P.; Xu, G.; Goh, S. H. Chemical Physics Letters 2001, 337, (13), 43-47.

40. Potschke, P.; Bhattacharyya, A. R.; Janke, A. European Polymer Journal 2004, 40, (1), 137-148.

41. Siochi, E. J.; Working, D. C.; Park, C.; Lillehei, P. T.; Rouse, J. H.; Topping, C. C.; Bhattacharyya, A. R.; Kumar, S. Composites Part B-Engineering 2004, 35, (5), 439446.

42. Tang, W. Z.; Santare, M. H.; Advani, S. G. Carbon 2003, 41, (14), 2779-2785.

43. Wilbrink, M. W. L.; Argon, A. S.; Cohen, R. E.; Weinberg, M. Polymer 2001, 42, (26), 10155-10180.

44. Fischer, J. E.; Zhou, W.; Vavro, J.; Llaguno, M. C.; Guthy, C.; Haggenmueller, R.; Casavant, M. J.; Walters, D. E.; Smalley, R. E. Journal Of Applied Physics 2003, 93, (4), 2157-2163.

45. Kimura, T.; Ago, H.; Tobita, M.; Ohshima, S.; Kyotani, M.; Yumura, M. Advanced Materials 2002, 14, (19), 1380-1383.

46. Zeng, J. J.; Saltysiak, B.; Johnson, W. S.; Schiraldi, D. A.; Kumar, S. Composites Part B-Engineering 2004, 35, (2), 173-178. 
47. Assouline, E.; Lustiger, A.; Barber, A. H.; Cooper, C. A.; Klein, E.; Wachtel, E.; Wagner, H. D. Journal Of Polymer Science Part B-Polymer Physics 2003, 41, (5), 520-527.

48. Grady, B. P.; Pompeo, F.; Shambaugh, R. L.; Resasco, D. E. Journal Of Physical Chemistry B 2002, 106, (23), 5852-5858.

49. Sandler, J.; Broza, G.; Nolte, M.; Schulte, K.; Lam, Y. M.; Shaffer, M. S. P. Journal Of Macromolecular Science-Physics 2003, B42, (3-4), 479-488.

50. Xiao, K. Q.; Zhang, L. C. Journal Of Materials Science 2004, 39, (14), 4481-4486.

51. Valentini, L.; Puglia, D.; Frulloni, E.; Armentano, I.; Kenny, J. M.; Santucci, S. Composites Science And Technology 2004, 64, (1), 23-33.

52. Schadler, L. S.; Giannaris, S. C.; Ajayan, P. M. Applied Physics Letters 1998, 73, (26), 3842-3844.

53. Sandler, J.; Shaffer, M. S. P.; Prasse, T.; Bauhofer, W.; Schulte, K.; Windle, A. H. Polymer 1999, 40, (21), 5967-5971.

54. Martin, C. A.; Sandler, J. K. W.; Windle, A. H.; Schwarz, M. K.; Bauhofer, W.; Schulte, K.; Shaffer, M. S. P. Polymer 2005, 46, (3), 877-886.

55. Martin, C. A.; Sandler, J. K. W.; Shaffer, M. S. P.; Schwarz, M. K.; Bauhofer, W.; Schulte, K.; Windle, A. H. Composites Science And Technology 2004, 64, (15), 23092316.

56. Liao, Y. H.; Marietta-Tondin, O.; Liang, Z. Y.; Zhang, C.; Wang, B. Materials Science And Engineering A-Structural Materials Properties Microstructure And Processing 2004, 385, (1-2), 175-181.

57. Lau, K. T.; Lu, M.; Lam, C. K.; Cheung, H. Y.; Sheng, F. L.; Li, H. L. Composites Science And Technology 2005, 65, (5), 719-725.

58. Gojny, F. H.; Wichmann, M. H. G.; Kopke, U.; Fiedler, B.; Schulte, K. Composites Science And Technology 2004, 64, (15), 2363-2371.

59. Allaoui, A.; Bai, S.; Cheng, H. M.; Bai, J. B. Composites Science And Technology 2002, 62, (15), 1993-1998.

60. Hull, D.; Clyne, T. W., An Introduction to Composite Materials. Second Edition ed.; Cambridge University Press: Cambridge, UK, 1996.

61. Morawetz, H., Polymer Monographs. ed.; Gordon and Breach Science Publishers: New York, 1968; Vol. 2.

62. Karger-Kocsis, J., Polypropylene: An A-Z reference. ed.; Kluwer Academic Publishers: Boston, 1999.

63. Broda, J. Journal Of Applied Polymer Science 2003, 89, (12), 3364-3370.

64. Valentini, L.; Biagiotti, J.; Kenny, J. M.; Santucci, S. Journal Of Applied Polymer Science 2003, 87, (4), 708-713.

65. Valentini, L.; Biagiotti, J.; Kenny, J. M.; Santucci, S. Composites Science And Technology 2003, 63, (8), 1149-1153.

66. Xia, H. S.; Wang, Q.; Li, K. S.; Hu, G. H. Journal Of Applied Polymer Science 2004, 93, (1), 378-386.

67. Coleman, J. N.; Cadek, M.; Blake, R.; Nicolosi, V.; Ryan, K. P.; Belton, C.; Fonseca, A.; Nagy, J. B.; Gun'ko, Y. K.; Blau, W. J. Advanced Functional Materials 2004, 14, (8), 791-798. 
68. Kearns, J. C.; Shambaugh, R. L. Journal Of Applied Polymer Science 2002, 86, (8), 2079-2084.

69. Moore, E. M.; Ortiz, D. L.; Marla, V. T.; Shambaugh, R. L.; Grady, B. P. Journal Of Applied Polymer Science 2004, 93, (6), 2926-2933.

70. McCrum, N. G.; Buckley, C. P.; Bucknall, C. B., Principles of Polymer Engineering. Second ed.; Oxford University Press: New York, 1997. 